\title{
LA EXTRATERRITORIALIDAD DE LAS ACTUACIONES JURÍDICO-ADMINISTRATIVAS DE LAS COMUNIDADES AUTÓNOMAS
}

\author{
JORGE AGUDO GONZÁLEZ \\ Universidad Autónoma de Madrid \\ jorge.agudo@uam.es
}

\author{
Cómo citar/Citation \\ Agudo González, J. (2018). \\ La extraterritorialidad de las actuaciones \\ jurídico-administrativas de las comunidades autónomas. \\ Revista de Administración Pública, 206, 99-145. \\ doi: https://doi.org/10.18042/cepc/rap.206.04
}

\section{Resumen}

El reconocimiento de efectos jurídicos extraterritoriales a actuaciones administrativas de las comunidades autónomas es habitual en nuestro ordenamiento, sin perjuicio de admitir, al mismo tiempo, que el principio de territorialidad ordena el sistema constitucional de distribución de competencias. De hecho, en el ordenamiento español cabe identificar hasta cuatro tipos de extraterritorialidad diferentes. Sin perjuicio de los matices según cada tipo, se puede afirmar que esa realidad jurídica comparte modelo regulativo y elementos estructurales con un principio del derecho europeo que ordena situaciones similares, aunque en contextos transnacionales: el principio de reconocimiento mutuo. Este estudio muestra que, con independencia del nomen iuris, en ambos casos la operatividad del reconocimiento depende de la previa equivalencia entre ordenamientos, así como de la selección de la norma aplicable con base en el criterio del país de origen. Del mismo modo, en ambos contextos el reconocimiento se manifiesta con variantes diversas, pero, en todo caso, se concretan en una gradación de automaticidad/condicionalidad. La STC 79/2017 ha negado este enfoque al analizar la constitucionalidad del principio de eficacia nacional que instauraba la Ley de Garantía de la Unidad de Mercado. Este estudio cuestiona la tesis del Tribunal, identificando las variantes del reconocimiento mutuo que deben considerarse inconstitucionales en función del tipo de extraterritorialidad. 


\title{
Palabras clave
}

Principio de territorialidad; extraterritorialidad; actuaciones jurídico-administrativas de las CC. AA.; principio de reconocimiento mutuo; equivalencia; país de origen.

\begin{abstract}
The recognition of extraterritorial legal effects to the administrative actions of the Autonomous Communities is common in our legal system. Notwithstanding, the principle of territoriality governs the constitutional system of distribution of public power. In fact, up to four types of extraterritoriality can be identified. In general terms, these legal phenomena share the same normative model and structural elements with the principle of mutual recognition of European Law. The study shows that, leaving aside the nomen iuris, in both cases the recognition depends on the previous equivalence between legal orders, as well as the selection of the enforcing provision based on the criterion of the country of origin. Notwithstanding the above, there are several mutual recognition variants according to a gradation of automaticity/conditionality of the recognition action. The Constitutional Court Judgment $79 / 2017$ has nevertheless denied this approach while analyzing the principle of national effectiveness established by the Guarantee of the Market Unit Act. This paper contests the Court's thesis, identifying those mutual recognition variants which are not constitutional depending on the type of extraterritoriality.
\end{abstract}

\section{Keywords}

Principle of territoriality; extraterritoriality; legal-administrative actions of Autonomous Communities; principle or mutual recognition; equivalence; country of origin. 


\section{SUMARIO}

I. INTRODUCCIÓN. II. TERRITORIALIDAD Y DISTRIBUCIÓN DE COMPETENCIAS:

1. Doctrina constitucional general sobre el principio de territorialidad. 2. Naturaleza de los efectos extraterritoriales: efectos jurídicos y/o fácticos. 3. Delimitación de la realidad jurídica y análisis normativo y jurisprudencial: 3.1. Extraterritorialidad plena. 3.2. Extraterritorialidad horizontal. 3.3. Extraterritorialidad convencional. 3.4. Extraterritorialidad unilateral. III. PARALELISMO CON EL RECONOCIMIENTO MUTUO: 1. Planteamiento de la cuestión. 2. Sobre el reconocimiento mutuo en el derecho europeo: 2.1. Variantes del reconocimiento mutuo. 2.2. Apunte sobre el principio de reconocimiento mutuo como principio ordenador de una Administración funcionalmente integrada. IV. ENCAJE CONSTITUCIONAL DEL RECONOCIMIENTO MUTUO COMO FÓRMULA PARA ARTICULAR LA EXTRATERRITORIALIDAD:

1. Planteamiento de la cuestión. 2. La doctrina de la STC 79/2017. 3. Análisis crítico. 4. Propuesta de un modelo alternativo.

\section{INTRODUCCIÓN}

La extraterritorialidad de los efectos de las actuaciones jurídico-administrativas de las CC. AA. ha venido centrando la atención de la doctrina focalizada en las controversias competenciales con el Estado. En los últimos años, ese interés ha incorporado nuevos contenidos vinculados a la generalización que algunas leyes estatales han llevado a cabo del reconocimiento de esa eficacia extraterritorial ${ }^{1}$. En este trabajo abordaremos el análisis pormenorizado de esta realidad jurídica.

El planteamiento de esta cuestión se hará tratando de justificar que, en términos generales y sin perjuicio de los matices que se expondrán, estos fenómenos jurídicos comparten modelo regulativo y elementos estructurantes con el principio de reconocimiento mutuo del derecho europeo. La relevancia

1 Pensamos en la Ley 17/2009, de 23 de noviembre, sobre el libre acceso a las actividades de servicios (Ley de Servicios), pero también en la Ley 25/2009, de 22 de diciembre («Ley ómnibus» de la Ley de Servicios), así como en la Ley 20/2013, de 9 de diciembre, de garantía de la unidad de mercado (LGUM). 
de la STC 79/2017 en este específico tema hará que nuestra exposición también sirva para cuestionar los argumentos del tribunal. En esta dirección, se propondrá una tesis distinta acerca de los parámetros constitucionales habilitantes del reconocimiento de eficacia extraterritorial, con base en un parangón con las variantes del reconocimiento mutuo.

\section{TERRITORIALIDAD Y DISTRIBUCIÓN DE COMPETENCIAS}

\section{DOCTRINA CONSTITUCIONAL GENERAL SOBRE EL PRINCIPIO DE TERRITORIALIDAD}

La doctrina constitucional ha reiterado que la atribución de competencias a las CC. AA. y su ejercicio se fundamenta en el principio de territorialidad, insistiendo en que este principio se encuentra implícito en el sistema de distribución de competencias constitucional ${ }^{2}$. Esto significa, como sucedía ya en las construcciones más elaboradas de la teoría general del Estado, que el territorio ostenta una doble vertiente en la determinación de quién y cómo se ostenta el poder público: es base y soporte de atribución y, al mismo tiempo, es límite (espacial) de la competencia.

La primera de las vertientes indicadas implica que las competencias son atribuidas a las CC. AA. porque afectan a fenómenos, acontecimientos, bienes, personas, situaciones y relaciones jurídicas que tienen lugar en su territorio $^{3}$. Aquí, cabe deducir una relación de conexión entre la atribución de competencias y la delimitación de su objeto, en virtud de un criterio territorial que presume la existencia de intereses autonómicos que legitiman que sean las CC. AA. las que asuman el ejercicio del poder público.

Las normas y resoluciones aprobadas y dictadas por las CC. AA. limitan su validez al territorio autonómico, esto es, allí donde tienen lugar aquellos hechos que son objeto de sus competencias. Desde este punto de vista, y como hemos anticipado, el territorio constituye el límite espacial de validez de las disposiciones y actuaciones jurídico-públicas de las CC. AA.: no hay competencias sin territorio y, por ello, no hay competencias más allá del territorio ${ }^{4}$.

El reparto de competencias se ajusta por jurisdicciones territoriales a nivel autonómico por otro motivo evidente. La atribución de competencias en

2 SSTC 13/1988 (FJ 2), 48/1988 (FJ 44), 49/1988 (FJ 30), 40/1998 (FJ 45), 80/2012, $79 / 2017$, etc.

3 La STC 79/2017 (FJ 13.a) resume la doctrina al respecto. En este sentido, también, el art. 157.2 CE.

4 Esta apreciación ya en la STC 99/1986 (FJ 4). 
las CC. AA. presume que los mismos hechos o fenómenos que son objeto y que justifican esa atribución competencial se pueden reproducir en las diecisiete CC. AA. Esto significa que todas ellas pueden asumir y ejercer competencias sobre materias idénticas. Esta obviedad permite aseverar que solo una atribución territorializada de competencias habilita y hace compatible un ejercicio simultáneo por todas las CC. AA .

Esto nos lleva a la segunda vertiente caracterizadora del territorio: la que le define como límite espacial en el que se ejercen las competencias. Esta vertiente supone, asumiendo una aplicación rigurosa del principio de territorialidad, que las CC. AA. solo pueden ejercer sus competencias dentro de su jurisdicción territorial. Es decir, la eficacia y vigencia de las actuaciones administrativas dictadas conforme a las normas válidas en un territorio se limitaría a ese ámbito de atribución del poder público descentralizado.

A pesar del aparente rigor con que asume la doctrina constitucional el paradigma de la territorialidad, lo cierto es que ese principio queda bastante relativizado en la vertiente que ahora abordamos. De hecho, podría decirse que el TC admite que el reconocimiento de efectos extraterritoriales imputables a las actuaciones jurídico-administrativas autonómicas es consustancial al modelo territorial español. En ningún caso parece que pueda decirse que constituya una manifestación excepcional ${ }^{6}$. Con cierta contradicción, la doctrina constitucional combina el recurso a ese calificativo ("excepcional») con alegatos a favor de una interpretación flexible del principio de territorialidad, ligados a argumentos que están dirigidos a proteger las competencias autonómicas de un eventual vaciamiento ${ }^{7}$.

En esta dirección, en frecuentes ocasiones el tribunal ha justificado la competencia de las CC. AA. en escenarios supraterritoriales. La normalidad de la atribución de competencias en esos supuestos encuentra su plasmación en una reiteradísima doctrina constitucional que establece una ausencia de co-

5 Como recordara tempranamente la STC 44/1984 (FJ 2).

6 En ese sentido, E. Aja, J. Tornos, T. Font, J. M. Perulles y E. Albertí (1985), El sistema jurídico de las Comunidades Autónomas, Madrid: Tecnos, págs. 430 y ss., S. Muñoz Machado (2007), Derecho Público de las Comunidades Autónomas, Madrid: Iustel, pág. 235, L. Pomed Sánchez (2007), "Competencias y territorio en los nuevos estatutos de autonomía», en Informe Comunidades Autónomas 2007, págs. 109-125 (pág. 117), L. Arroyo Jiménez (2007), «El principio de territorialidad», en F. Balaguer (dir.), Reformas estatutarias y distribución de competencias, Sevilla: IAAP, pág. 102, o M. Vaquer Caballería (2010), La eficacia territorial y temporal de las normas, Valencia: Tirant lo Blanch, pág. 35. Más matizadamente, C. I. Velasco Rico (2012), Delimitación de competencias en el estado autonómico y puntos de conexión, Barcelona: IEA, págs. 48 y ss. Así ya desde la STC 165/1985 (FJ 3). 
rrespondencia entre supraterritorialidad del objeto de las competencias y atracción de la misma a favor del Estado ${ }^{8}$. La doctrina constitucional reivindica el fraccionamiento del objeto de la competencia y, en última instancia, el recurso a mecanismos de cooperación o de coordinación como solución?. Por tanto, la supraterritorialidad no es óbice para la territorialización de la competencia ${ }^{10}$.

Esa doble vertiente de la territorialidad a la que venimos aludiendo, así como su flexibilización en los términos recién comentados, también tiene su constatación en los Estatutos de Autonomía ${ }^{11}$. Cabe distinguir dos grupos de CC. AA.:

10) Aquellas CC. AA. cuyos Estatutos no incluyen cláusulas pormenorizadas relativas al alcance territorial de las competencias ${ }^{12}$. Los nuevos Estatutos de algunas de esas CC. AA. a lo sumo hacen una referencia general a la eficacia de las normas jurídicas de las CC. AA., incluyendo alusiones a una eventual eficacia «extraterritorial» ${ }^{13}$.

20) Las CC. AA. de Cataluña, Andalucía y Aragón, cuyos Estatutos (arts. 115,43 y 70, respectivamente) mantienen, dejando a un lado los matices, una estructura regulatoria común por lo que se refiere al alcance territorial de sus competencias: a) Regla general: las CC. AA. ejercen sus competencias con plena eficacia en su territorio, porque el objeto de las mismas se limita a ese ámbito espacial; b) Primera excepción: los Estatutos de Autonomía u otra disposición legal estatal pueden conferir

8 Las SSTC 194/2011, 244/2012, 22/2014, 27/2014 88/2014, 61/2015 o 178/2015 reiteran esta doctrina.

9 La STC 31/2010 (FJ 63) sintetiza la doctrina constitucional.

10 En esa proyección extraterritorial de las competencias autonómicas cobra especial relevancia el recurso a los "puntos de conexión» establecidos por el legislador estatal. Estos puntos de conexión cumplen una doble función: a) constituyen un criterio de atribución competencial que permite identificar la única entidad territorial competente y, por ello, el único ordenamiento válido aplicable. Por todas, la STC 95/2013 (FJ 7). En una línea similar, X. Arzoz Santiesteban (2002), «Comunidades autónomas, puntos de conexión y defensa de la competencia», Revista Vasca de Administración Pública, 64, págs. $7-57$ (pág. 13), L. Pomed Sánchez (2007: 120) o C. I. Velasco Rico (2012: $147-148$ y 154); y b) son la base para la proyección extraterritorial de los efectos de las competencias autonómicas territorializadas. Por todas, la STC 27/2014 (FJ 4).

11 Véanse L. Pomed Sánchez (2007) y C. I. Velasco Rico (2012).

12 Aquí estarían Islas Baleares, Comunidad Valenciana, Castilla y León, Extremadura o Navarra.

13 Así, el art. 7.2 del Estatuto de la Comunidad Valenciana, y el art. 2 del Estatuto de Extremadura. 
eficacia extraterritorial a los actos y normas de esa comunidad autónoma; y c) Segunda excepción: cuando el objeto de una competencia supere el territorio de la comunidad, el ejercicio de las competencias se limitará al territorio de la misma, sin perjuicio de que mediante instrumentos convencionales o a través de la coordinación del Estado puedan articularse mecanismos para que sean ejercidas más allá de su territorio.

Tanto del repaso de la doctrina constitucional como de los Estatutos de Autonomía cabe derivar una conclusión evidente: la flexibilidad con que se asume el principio de territorialidad en nuestro ordenamiento. En este sentido, se puede afirmar que este principio constituye un límite relativo $^{14}$ : a) porque la supraterritorialidad no impide la territorialización de competencias, $\mathrm{y}$ b) porque los efectos derivados del ejercicio de las competencias autonómicas no necesariamente tienen como límite el territorio de cada comunidad autónoma.

\section{NATURALEZA DE LOS EFECTOS EXTRATERRITORIALES: EFECTOS JURÍDICOS Y/O FÁCTICOS}

¿Qué tipo de efectos con trascendencia extraterritorial son considerados compatibles con el sistema constitucional de distribución de competencias? La STC 27/2014 (FJ 4) reitera una consolidada doctrina en la materia, en virtud de la cual las normas y actos de las CC. AA. pueden producir «consecuencias de hecho en otros lugares del territorio nacional» $»^{15}$. Es decir, una interpretación literal de la doctrina constitucional llevaría a rechazar la constitucionalidad de aquellas disposiciones y actos que generasen efectos extraterritoriales de naturaleza jurídica. Sin embargo, esta conclusión es incorrecta.

Los ejemplos en nuestro ordenamiento y en la doctrina constitucional que admiten la generación de efectos jurídicos extraterritoriales, como tendremos ocasión de mostrar, son bastante reiterados. Es evidente que aquí se produce una clara contradicción entre la doctrina recién recordada y el resultado de múltiples sentencias en las que se corrobora la constitucionalidad de disposiciones que regulan el ejercicio de funciones administrativas que nece-

14 L. Pomed Sánchez (2007: 118) y C. I. Velasco Rico (2012: 41 y 44).

15 Esta doctrina en las SSTC 37/1981 (FJ 1) y 44/1984 (FJ 2), luego reiterada en muchas otras. Como se podrá deducir de nuestra exposición, esta doctrina solo es correcta en relación con los efectos que pueden generar las competencias cuyo objeto no es supraterritorial y, por este motivo, radica exclusivamente en el territorio de una comunidad. 
sariamente generan efectos jurídicos más allá del territorio de la comunidad autónoma autora del acto.

Antes de pasar a su examen, se nos permitirá hacer alusión a la STC $195 / 2001^{16}$. Esta sentencia destaca porque aborda un supuesto del que cabe deducir los límites dentro de los cuales el tribunal admite la constitucionalidad de la extraterritorialidad de los efectos jurídicos de las competencias ejercidas por las CC. AA. En este sentido, la sentencia (FJ 3) afirma que para que los efectos extraterritoriales de la norma o del acto dictado por una comunidad autónoma supongan una invasión competencial, deben concurrir tres circunstancias: $1^{\text {a)}}$ ) Que exista una «contradicción de derechos o deberes jurídicos por la incidencia en una actividad determinada tanto del acto o disposición propia como de un acto o disposición ajenos»; es decir, el Tribunal está pensando en una actuación unilateral de una comunidad generadora de una contradicción con el modo en que otra ordena esos mismos supuestos en su territorio; 2a) Que la disposición o el acto con incidencia en el ámbito de otra comunidad provoque efectos jurídicos y no simples efectos de hecho; y $3^{\text {a) }}$ Que se trate de efectos jurídicos con un contenido actual, nunca potencial o hipotético.

Con base en estos tres criterios, cabe derivar que la sentencia establece un claro límite a la constitucionalidad de los efectos jurídicos extraterritoriales: siempre que una comunidad autónoma dicte disposiciones o actos con eficacia jurídica unilateral y actual, cuyos efectos se extiendan más allá de su territorio, generando una contradicción con el modo en que otra comunidad ordena los mismos derechos o deberes jurídicos, existirá una invasión competencial. Ahora bien, de la propia sentencia también cabe deducir que, en otro caso, la eficacia jurídica extraterritorial de las actuaciones jurídico-administrativas de las CC. AA. es aparentemente compatible con la Constitución. Lógicamente, esta afirmación general ha a ser matizada según los casos, pero sí que permite encajar, como ya hemos anticipado, los muchos ejemplos en los que nuestro ordenamiento prevé supuestos similares y cuya compatibilidad con la Constitución ya ha sido confirmada por el propio Tribunal Constitucional.

16 El objeto de este conflicto positivo de competencias fue la nulidad de los Acuerdos de la Junta de Galicia relativos a un proyecto de obras de mejora del puerto de Ribadeo (Lugo). La Comunidad de Asturias mantenía que la aprobación y, singularmente, la ejecución del proyecto, aun cuando se ubicaba dentro de la comunidad autónoma gallega, invadía una serie de competencias atribuidas por su Estatuto. La sentencia enfatiza que la controversia se encuadra en una «lesión de hecho», consecuencia de la ejecución de la obra. Esto lleva a afirmar la inexistencia de la controversia competencial, entendiendo que se trata de un problema de legalidad ordinaria a dirimir por la jurisdicción contencioso-administrativa. 


\section{DELIMITACIÓN DE LA REALIDAD JURÍDICA Y ANÁLISIS NORMATIVO Y JURISPRUDENCIAL}

En los siguientes epígrafes abordaremos la tipología de supuestos en los que, siendo supraterritorial el objeto de una competencia, el ordenamiento prevé que la actuación jurídico-administrativa de las CC. AA. genere efectos jurídicos extraterritoriales ${ }^{17}$. Diferenciaremos cuatro tipos individualizados con base en los siguientes datos: a) la distribución de competencias entre Estado y CC. AA.; la clave se encontrará en quién ostenta las competencias para regular sustantivamente una materia, debiéndose distinguir los supuestos de competencias exclusivas estatales de aquellos otros en los que las competencias son compartidas o exclusivas de las CC. AA.; y b) los términos que habilitan el ejercicio territorializado de una competencia con objeto supraterritorial; aquí se distinguirán los casos en que la atribución de competencias ejecutivas se debe a la fijación por el legislador estatal de puntos de conexión, de aquellos otros en los que la competencia ejecutiva es exclusiva de las CC. AA.

\subsection{Extraterritorialidad plena}

En nuestro derecho positivo no es extraño que una norma estatal, con lógica validez y vigencia en toda Espańa, confiera esa misma caracterización a situaciones jurídicas reconocidas por las Administraciones autonómicas. Como regla general, se trata de normas que prevén que las CC. AA. dicten actos declarativos de derechos. Lo relevante es que la legislación estatal reconoce a esos actos una eficacia semejante a la que hubieran tenido de haber sido dictados por la Administración del Estado.

Estos supuestos coinciden con materias en las que el Estado ostenta competencias legislativas amplias, no necesariamente exclusivas, pero en las que el TC ha interpretado ya el pormenor al que puede llegar el legislador estatal. Este dato es crucial: la legislación estatal ordena sustantivamente la materia en cuestión, sin que, en el plano normativo, las CC. AA. puedan introducir condicionantes o nuevos requerimientos adicionales. Puede decirse, por tanto, que la regulación en la materia está armonizada en todo el territorio nacional gracias a la legislación estatal, y que es la Administración autonómica la que aplica esa normativa. Es cierto, no obstante, que esto no implica que el papel regulador de las CC. AA. sea inexistente. La incidencia del ordenamiento de

17 Los conceptos «supraterritorialidad» y «extraterritorialidad» son utilizados con el sentido jurídico deducible de la doctrina constitucional: «supraterritorialidad» será empleado para referirse al objeto de la competencia, y «extraterritorialidad» para calificar los efectos de su ejercicio. 
cada comunidad autónoma puede producirse en lo estrictamente formal, es decir, regulando lo organizativo y, en su caso, lo procedimental.

Un dato distintivo clave en estos supuestos es que la validez sustantiva de la decisión autonómica se fundamenta exclusivamente en el derecho estatal; por otra parte, la vigencia de las actuaciones jurídico-administrativas autonómicas se prolonga a todo el territorio español, gracias a la atribución de eficacia extraterritorial realizada directa y automáticamente por la legislación estatal. En consecuencia, la efectividad de las actuaciones de una comunidad autónoma en el territorio de otras se produce de forma inmediata y, por tanto, sin que medie ningún control previo (ni estatal, ni de otra Administración autonómica) que condicione el reconocimiento de dichas actuaciones.

Hemos afirmado que en los supuestos de «extraterritorialidad plena» las actuaciones administrativas autonómicas gozan de «validez sustantiva» en todo el territorio nacional. Esta afirmación necesita una aclaración. Es cuestionable, como se establece en los distintos ejemplos existentes en nuestro ordenamiento, que las actuaciones administrativas de las CC. AA. se puedan calificar, sin mayor precisión, como plenamente válidas en todo el territorio nacional ${ }^{18}$. Es necesario distinguir entre la validez sustantiva y formal del acto. Desde el plano material o sustantivo, la única legislación que determina la conformidad a derecho del acto es la legislación estatal. En esta vertiente, cabe decir, como hemos hecho, que la validez de la decisión autonómica se fundamenta en el derecho estatal. Sin embargo, desde el plano formal la decisión es adoptada por la autoridad autonómica competente y, en su caso, de acuerdo con los procedimientos desarrollados por la normativa de cada comunidad autónoma. En otras palabras, la validez formal del acto puede estar condicionada parcialmente por la legislación autonómica. Esto determina que solo la Administración que dicta el acto sea la competente para revisarlo y que, por este motivo, el acceso a la jurisdicción también quede condicionado por ese mismo dato. Ahora bien, insistimos en que, en el plano sustantivo, la actuación administrativa autonómica funda su validez en el derecho estatal y, por este motivo, la validez de la actuación administrativa podrá ser controlada, en última instancia, en vía casacional (art. 86.3.I LJCA).

Los términos en los que la legislación estatal reconoce efectos extraterritoriales a los actos declarativos de las Administraciones de las CC. AA. cambian según la materia, aunque en esencia los matices no son relevantes. Cabe distinguir dos tipos de supuestos:

18 En bastantes de los ejemplos que citaremos a continuación, la legislación estatal suele atribuir «validez en todo el territorio nacional» a la actuación correspondiente de la comunidad autónoma. 
10) Supuestos en los que el Estado opta por dotar expresamente de eficacia nacional a actuaciones jurídico-administrativas de las CC. AA., en materias en las que las CC. AA. ostentan competencias ejecutivas previamente transferidas o delegadas: a) la autorización autonómica de los planes de estudios que deben ser cursados para obtener un título con plena validez en toda España (art. 2.2.g LOU), tras la modificación de la LOU por LO 4/2007, de 13 de abril ${ }^{19}$; b) los certificados de profesionalidad emitidos por las CC. AA. que hayan recibido el traspaso de la gestión del Plan nacional de formación e inserción profesional, de acuerdo con los arts. 1.2 y 8.1 del Real Decreto 1506/2003, de 28 de noviembre ${ }^{20}$; c) el reconocimiento, declaración y calificación del grado de minusvalía, de conformidad con el art. 4.3 del Real Decreto Legislativo 1/2013, de 29 de noviembre, texto refundido de la Ley General de derechos de las personas con discapacidad y de su inclusión social ${ }^{21}$, en relación con el art. 6 Real Decreto 1971/1999, de 23 de diciembre; d) la autorización de las empresas de trabajo temporal con centros de trabajo únicamente en el territorio de una comunidad, en los términos de los arts. 2.1 y 4.2 de la Ley 14/1994, de 1 de junio, según redacción otorgada por la Ley 18/2014, de 15 de octubre ${ }^{22}$; e) las autorizaciones de los almacenes de residuos nucleares y radioactivos reguladas en el Real Decreto $1836 / 1999$, de 3 de diciembre ${ }^{23}$; y f) el otorgamiento de autorizaciones para la prestación de los servicios de transporte público discrecional de viajeros, mercancías o mixtos, cuyo ámbito territorial exceda de una co-

19 Esta es una de las "fases de tramitación» que ordena el procedimiento para el establecimiento de los títulos oficiales (STC 176/2015, FJ 4). La extraterritorialidad de la actuación autonómica no es un corolario inherente al reparto de competencias. El Estado, con base en su competencia exclusiva (art. 149.1.30), podría haber mantenido otros sistemas, como el basado en mecanismos de homologación. Así sucedía, por ejemplo, a la vista de la redacción original de los arts. 34 y 35 LOU.

La adecuación del ejercicio de la competencia estatal al sistema constitucional fue validada por la STC 194/2012. La sentencia recuerda (FJ 6) que la norma que aquí nos interesa fue dictada con base en la competencia exclusiva que le atribuye el art. 149.1.7, lo que para el Tribunal es clave.

21 Dictado con base en el art. 149.1.1 y 6 CE.

22 Dictada con base en el art. 149.1.7, 13 y 17 CE, para adaptar la ley a la LGUM. Entiéndase ahora esta cita sin atender a la eventual repercusión de la jurisprudencia constitucional dictada sobre la LGUM.

La STC 14/2004 (FJ 13) declara que la autorización de las instalaciones de segunda y tercera categoría compete a las CC. AA. «cuando tengan transferidas dichas funciones», con plena eficacia extraterritorial. 
munidad autónoma, con base en el art. 5.a) LO 5/1987, de 30 de julio, por la que se procedió a la delegación en las CC. AA. (art. 150.2 CE), en el marco de la Ley 16/1987, de 30 de julio, de Ordenación de los Transportes Terrestres ${ }^{24}$.

$\left.2^{\circ}\right)$ Supuestos en los que las CC. AA. ostentan competencias de ejecución originariamente propias, es decir, sin que medie previa transferencia ad hoc. A diferencia del grupo anterior, aquí no siempre existe una norma que declare la eficacia o la "validez» en todo el territorio nacional de la actuación administrativa de las CC. AA. Esa consecuencia es deducible al interpretar la normativa estatal en la materia, como así ha corroborado en muchos casos el TC: a) la autorización para la anotación registral y posterior comercialización en toda España de los productos alimentarios no peligrosos en el marco del Real Decreto 2825/1981, de 27 de noviembre, por el que se regula el registro general sanitario en materia alimentaria ${ }^{25}$; b) la actuación ejecutiva en las distintas fases en que la Ley 3/1985, de 18 de marzo, de Metrología (ahora derogada), descomponía el control metrológico (at. 7.5 ${ }^{26}$ ); c) la acreditación de los organismos de evaluación de la conformidad conforme a los arts. 15.2 y 19.3 de la vigente Ley 32/2014, de 22 de diciembre, de Metrología ${ }^{27}$; d) la acreditación de la competencia técnica de los organismos de control en el ámbito de la seguridad industrial regulado por la Ley 21/1992, de 16 de julio, de Industria, según la modificación realizada por Ley 32/2014, de 22 de diciembre ${ }^{28}$; e) las funciones de homologación en el marco del apartado 4.1.4.II del Real Decreto 2584/1981, de 18 de septiembre, Reglamento

24 En la STC 118/1996 (FJ 1) se reconoce la extraterritorialidad de estas autorizaciones. En relación con la autorización e inscripción de productos alimentarios, el Real Decreto solo se refería a la de los aditivos y demás productos peligrosos para la salud, para los que reservaba la competencia al Estado. Sin embargo, no incluyó normas sobre la autorización de productos alimentarios no peligrosos. La STC 87/1985 (FJ 5) resolvió el recurso de inconstitucionalidad interpuesto contra la Ley catalana 15/1983, de 14 de julio, de higiene y control alimentarios, considerando que es una competencia en materia sanitaria que corresponde a la Generalidad de Cataluña, aplicando la normativa estatal. La STC 100/1991 (FJ 3) reconoció la competencia autonómica en una materia de competencia exclusiva estatal (art. 149.1.12). Posteriormente, la STC 236/1991 (FJ 5) se pronunció sobre el art. 7.5, señalando que prevé «un razonable reconocimiento de la eficacia extraterritorial».

27 La constitucionalidad del precepto ha sido ratificada por la STC 117/2017 (FJ 4 y 5).

28 La legalidad de esta exigencia ha sido ratificada por STS de 4 de abril de 2017 (Rec. 4467/2015). 
General de normalización y homologación, según redacción dada por el Real Decreto 105/1988, de 12 de febrero ${ }^{29}$; f) la actuación administrativa de homologación en materia de aparatos que utilizan gas como combustible, aprobado por Real Decreto 494/1988, de 20 de mayo ${ }^{30}$; g) la autorización de las entidades de inspección y control reglamentario en materia de seguridad de los productos, equipos e instalaciones industriales, regulada por el Real Decreto 1407/1987, de 13 de noviembre ${ }^{31}$; y h) las calificaciones de películas de acuerdo con el art. 6.3 del Real Decreto 1084/2015, de 4 de diciembre ${ }^{32}$, y el art. 8 de la Ley 55/2007, de 28 de diciembre, del Cine ${ }^{33}$.

\subsection{Extraterritorialidad horizontal}

En estos casos la clave se encuentra en la correlación entre órdenes normativos que no guardan relaciones de prevalencia o de primacía entre sí; dos ordenamientos, además, que podrían ser aplicados a priori a una misma situación o relación jurídica, debido a que esta se caracteriza por tener conexiones con varios territorios. Aquí, por tanto, la clave es determinar qué norma es la aplicable en virtud de los puntos de conexión establecidos y, consecuentemente, qué Administración será la competente para aplicar dicha norma y, a continuación, ser objeto de reconocimiento en otras CC. AA.

Estos supuestos coinciden con ámbitos de competencias compartidas: a) esas actuaciones administrativas son dictadas con sujeción a una legislación

29 La STC 313/1994 (FJ 3) resuelve el conflicto positivo de competencias confirmando la competencia autonómica y reconociéndole eficacia extraterritorial.

30 La STC 313/1994 (FJ 7) también considera que las competencias corresponden a las CC. AA. con efectos jurídicos extraterritoriales.

31 La STC 243/1994 (FJ 6) resuelve el conflicto positivo de competencias contra el Real Decreto admitiendo la competencia de las CC. AA., aun cuando las entidades actúen en más de una comunidad.

32 El precepto fue dictado con base en el art. 149.1.1º. Además, Estado y CC. AA. gozan de competencias concurrentes con base en el art. 149.2 CE, en los términos de la STC 122/2014 (FJ 3.b).

33 Este ejemplo es controvertido y podría explicarse como un supuesto de «extraterritorialidad horizontal». El hecho de que las administraciones de las CC. AA. apliquen derecho estatal y, en este concreto punto, la ordenación autonómica sea irrelevante, es el motivo para que sea incluido en este grupo. Concretamente, algunas CC. AA. han aprobado sus propias Leyes del Cine, pero, en este aspecto, no hay innovación sustantiva alguna (véase el art. 12.1 Ley 20/2010, de 7 de julio, de Cataluña). 
estatal que no agota materialmente la regulación, de modo que la legislación autonómica no se limita a disposiciones organizativas o procedimentales, sino que es determinante en la pormenorización sustantiva del régimen jurídico. Así pues, las decisiones adoptadas por las Administraciones autonómicas serán válidas si también cumplen en lo sustantivo con la legislación autonómica. Por ello mismo, la única Administración competente para revisarlas será la de esa comunidad y, esto, lógicamente, condiciona tanto el acceso a la jurisdicción como la culminación a priori del control jurisdiccional en cada Tribunal Superior de Justicia; y b) el Estado ejerce funciones de coordinación y armonización parcial que le facultan para conectar los ordenamientos de las CC. AA., habilitando que sus actuaciones administrativas puedan gozar de eficacia extraterritorial. Esa eficacia es reconocida, con mayor o menor grado de automaticidad, previo control por parte de la Administración del resto de CC. AA.

El paralelismo de estos supuestos con el reconocimiento mutuo es bastante claro. No es de extrañar que los ejemplos en nuestro ordenamiento estén casi siempre ligados a la ejecución de normas de derecho europeo. Sin embargo, ninguno de los ejemplos siguientes se caracteriza por tener esa conexión supranacional:

a) Un ejemplo ya clásico es el analizado por la STC 49/1988 (FJ 30). Estaba en entredicho la atribución al Ministerio de Economía y Hacienda y al Banco de España de las funciones de disciplina, inspección y sanción de las cajas de ahorros, de acuerdo con la D. Ad. 1a Ley 31/1985, de 2 de agosto $^{34}$. Téngase en cuenta que la ley estatal se centraba en la organización interna de las cajas, mientras que debían ser las leyes autonómicas las que regularan la autorización y el ejercicio de la actividad. La sentencia consideró que aquellas funciones correspondían a la comunidad de acogida, incluso para las cajas que tuvieran su domicilio social en otra comunidad. Sensu contrario esto significaba que la autorización de creación de las cajas era competencia de la comunidad de origen ${ }^{35}$. Con esa autorización podían realizar su actividad en toda España, abriendo sucursales ${ }^{36}$ sobre las

34 Derogada por la Ley 26/2013, de 27 de diciembre, de cajas de ahorros y fundaciones bancarias.

35 Así, los arts. 7 a 10 de la Ley 4/2003, de 11 de marzo, de Cajas de Ahorros de la Comunidad de Madrid, o el art. 6.2 de la Ley 15/1999, de 16 de diciembre, de Cajas de Ahorros de Andalucía.

36 En este sentido, el art. 16.1 de la Ley de Cajas de Ahorros de la Comunidad de Madrid. El art. 60 Decreto Legislativo 1/2005, de 10 de marzo, por el que se aprueba el texto refundido de las Leyes de Cajas de Ahorros de Galicia, afirma que «las Cajas de Ahorros gallegas podrán abrir oficinas en cualquier parte del territorio del Estado...", lo 
que la comunidad de acogida ejercería sus funciones de disciplina, inspección y sanción ${ }^{37}$.

b) La tarjeta de estacionamiento para personas con discapacidad regulada en el Real Decreto 1056/2014, de 12 de diciembre ${ }^{38}$, en el que se establecen las condiciones básicas de emisión y uso ${ }^{39}$. Alguna norma autonómica dictada después de la estatal se ha limitado a transponer lo dispuesto por ella ${ }^{40}$, lo que podría inducir a pensar que la norma reglamentaria estatal agota la regulación en la materia. Sin embargo, esto es correcto, pues las CC. AA. ostentan competencias para llevar a cabo una ordenación pormenorizada ${ }^{41}$. Esta conclusión es la que nos permite afirmar que las tarjetas son otorgadas por la Administración de residencia con base en su propia norma, en el marco de las condiciones básicas del Real Decreto, siendo eficaces en toda Espańa (art. 4).

c) La colegiación obligatoria en los casos en que la profesión esté organizada por colegios territoriales ${ }^{42}$, de conformidad con el art. 5.5 «Ley ómnibus» de la Ley de Servicios, que modificó el art. 3 de la Ley 2/1974, de 13 de febrero, de Colegios Profesionales. En estos casos, el art. 3.3 prevé que la primera colegiación habilitará al ejercicio de la actividad profesional en toda España. A tal efecto, los colegios territoriales aplican la legislación

que, en buena lógica, no puede suponer la exclusión de las funciones de autorización y control por las CC. AA. de acogida.

37 En el sentido, por ejemplo, del art. 36 de la Ley de Cajas de Ahorros de Andalucía.

38 Téngase en cuenta que, en esta materia, había sido dictada la Recomendación (98/376/

CE) del Consejo, de 4 de junio de 1998, relativa a la necesidad del reconocimiento mutuo por los Estados miembros de la Unión Europea de la tarjeta de estacionamiento para personas con discapacidad. La especialidad de las recomendaciones en el sistema de fuentes es la que nos permite ubicar este ejemplo en este listado.

39 Fue dictado con base en el art. 149.1.1 CE, vinculado al ejercicio del derecho previsto en el art. 19 CE.

40 Un buen ejemplo en los arts. 2 y 3, Decreto 47/2015, de 7 de mayo, de la Comunidad de Madrid.

41 La STC 18/2017 (FJ 7) así lo afirma rotundamente.

42 El sistema actual de colegiación distingue entre la colegiación voluntaria y la obligatoria. La colegiación es un derecho siempre y cuando se ostente la titulación requerida y reúna las condiciones señaladas estatutariamente, pero también es, como dispone el art. 3.2, un "requisito indispensable para el ejercicio de las profesiones», ahora bien, solo "cuando así lo establezca una Ley estatal». Se puede decir que la colegiación voluntaria es la regla general, y aquí las CC. AA. ostentan plenas competencias. Sin embargo, tal y como ha reiterado la jurisprudencia constitucional, el Estado sí ostenta la competencia para ordenar la colegiación obligatoria (SSTC 3/2013, 46/2013, 50/2013, 63/2013 o 89/2013). 
estatal ${ }^{43}$, verificando si se ostenta la titulación requerida, pero también aplican normas aprobadas por las CC. AA. y la propia Administración corporativa territorial, ya que se ha de comprobar que se reúnen las condiciones establecidas estatutariamente.

d) Un supuesto de extraterritorialidad especial por razón de quien emite el acto al que se le imputan tales efectos es el de la «licencia única deportiva». Esta licencia habilita a la participación en cualquier competición deportiva oficial de ámbito estatal regulada en el art. 32.4 de la Ley 10/1990, de 15 de octubre, del Deporte, según la redacción otorgada por la Ley 15/2014, de 16 de septiembre, de racionalización del sector público y otras medidas de reforma administrativa. Este es un supuesto singular, porque la licencia es otorgada por las federaciones autonómicas que, como recordara la STC 80/2012 (FJ 9), son organizaciones deportivas de carácter privado, independientemente de que puedan ejercer funciones públicas por «delegación». Entiéndase, por tanto, la cita de este ejemplo partiendo de esta peculiaridad.

De acuerdo con la interpretación otorgada por la STC 33/2018 (FJ 3.f) del citado art. 32.4, la licencia deportiva autonómica será expedida por las federaciones deportivas de ámbito autonómico integradas en la correspondiente federación estatal, ańadiendo que la «licencia producirá efectos» exclusivamente "en las competiciones oficiales de ámbito estatal en los ámbitos estatal» ${ }^{44}$. El art. 32.4 último inciso aclara que el efecto

43 Esta conclusión se deduce, por ejemplo, de la STC 170/2014 (FJ 6), al albur del análisis de constitucionalidad del sistema de evaluación para el acceso a la abogacía y a la procura.

44 Sin perjuicio de las particularidades del supuesto, se trata de un caso de difícil clasificación, sobre todo por la automaticidad con que tiene lugar el reconocimiento de efectos extraterritoriales. El motivo para incluirlo entre los ejemplos de «extraterritorialidad horizontal» se debe a la especial distribución competencial en la materia y a las potestades normativas que ostentan las CC. AA. para detallar la regulación estatal. La competencia estatal para regular la «licencia única deportiva» es fundamentada en la reconocida por la STC 80/2012. Esta última sentencia afirmó que, a pesar de que no exista un título competencial específico que otorgue competencias al Estado, y de que esta sea una competencia exclusiva de las CC. AA., esto «no significa que el Estado no pueda intervenir, en concurrencia con las Comunidades Autónomas, en la regulación del deporte», siempre y cuando se circunscriba a los «intereses generales» del «deporte español en su conjunto» (STC 80/2012, FJ 8). La STC 33/2018 fundamenta que la estructura organizativa federativa de tipo asociativo y piramidal contribuye a que «el denominado efecto 'vertical' de una licencia deportiva autonómica, esto es, la habilitación que ésta otorga a su titular para participar en competiciones oficiales de ámbito estatal, pueda encontrar cobertura 
extraterritorial de la licencia autonómica se produce «desde el momento en que se inscriba en el registro de la federación deportiva autonómica».

e) Por último, la LGUM es sin duda el mejor ejemplo ${ }^{45}$. A diferencia de los anteriores, la ley asume un ámbito de aplicación muy amplio. No obstante, su operatividad es parecida y, en todo caso, es similar a la de cualquier norma de derecho derivado europeo que incorpore mecanismos de reconocimiento mutuo ${ }^{46}$ : a) la actuación de intervención de la «autoridad de origen ${ }^{47}$ es la determinante del acceso a una actividad (art. 19); consecuentemente, el ordenamiento aplicable es el de esa comunidad; b) las actuaciones administrativas de la Administración de origen tienen eficacia extraterritorial y gozan de efectos jurídicos en toda España (arts. 6, 19 y 20); y c) la Administración de destino debe reconocer previa verificación/ supervisión dicha actuación, sin que pueda subordinarlo a un nuevo control equivalente al que ya fue sometido en origen (arts. 5, 17 y 18) ${ }^{48}$.

\subsection{Extraterritorialidad convencional}

Este grupo está conformado por aquellos supuestos en los que las CC. AA., recurriendo a fórmulas convencionales, logran que sus actuaciones jurí-

competencial en la gestión por el Estado de 'sus' intereses (art. $137 \mathrm{CE}$ ), incluyendo entre éstos los del 'deporte español en su conjunto' (STC 80/2012, FJ 8), y por tanto los de las competiciones oficiales de ámbito estatal». La sentencia, finalmente, restringe el efecto extraterritorial de la licencia deportiva en el que califica como efecto «transversal» $\mathrm{u}$ "horizontal», esto es, el que habilita para participar en competiciones oficiales de ámbito territorial autonómico, ya que ahí el Estado estaría "penetrando e incidiendo en intereses estrictamente autonómicos y, en consecuencia, perturbando el ejercicio de sus competencias por las Comunidades Autónomas».

45 Omitiremos en este momento los efectos de la STC 79/2017. La intención es mostrar los mecanismos que incorpora la ley para reconocer los efectos extraterritoriales de las actuaciones administrativas.

46 Esto mismo es trasladable a otras leyes modificadas para su adaptación a la LGUM. Es el caso, por ejemplo, de la Ley 7/1996, de 15 de enero, de Ordenación del Comercio Minorista, modificada por Ley 18/2014, de 15 de octubre, en virtud de la remisión que el art. 6.4.II hace a la Ley de Servicio y a la LGUM. Entiéndase, aquí también, esta cita sin atender a la eventual repercusión de la STC 79/2017.

47 Definida en el anexo de la LGUM como la «autoridad competente del lugar del territorio nacional donde el operador esté establecido legalmente para llevar a cabo una determinada actividad económica».

48 Otra cosa es que los términos en que la LGUM previó las facultades de la Administración de destino eran tan disminuidos que solo merecían su inconstitucionalidad. 
dico-administrativas gocen de eficacia jurídica en otras CC. AA. ${ }^{49}$. Su operatividad es similar a la del grupo anterior, pero con un matiz: aquí no interviene el Estado ni para regular la materia (pues carece de competencias; a lo sumo incide mediante sus títulos horizontales) ni para coordinar la relación entre ordenamientos autonómicos. Son las CC. AA. quienes establecen los mecanismos de cooperación que habilitan esas soluciones jurídicas ${ }^{50}$.

El entendimiento de la vía convencional como un instrumento para canalizar las situaciones generadoras de efectos extraterritoriales ha sido asumido con normalidad por la jurisprudencia constitucional ${ }^{51}$. Ahora bien, la particularidad de los convenios que aquí nos interesan hace que no presenten parangón ni con los convenios más comunes hasta la fecha ${ }^{52}$ ni con los llamados convenios normativos ${ }^{53}$. No obstante, aunque pocos, cabe citar algunos ejemplos. En todo ellos el convenio articula un mecanismo que permite el reconocimiento de la actuación de la Administración de origen al que se le otorga eficacia extraterritorial ${ }^{54}$ :

a) El convenio para el reconocimiento recíproco de los certificados de formación de los aplicadores de tatuajes, piercings y micropigmentaciones ${ }^{55}$. La cláusula $1^{\text {a }}$ establece que el objeto del convenio es «el reconocimiento recíproco» de «la validez de los certificados que acrediten la formación de los aplicadores» obtenidos en el resto de las CC. AA. Por otro lado, la cláusula $3^{a}$ regula los «Efectos del reconocimiento del certificado de formación", disponiendo que el certificado expedido en

49 En la línea de S. Muñoz Machado (2007: 234 y ss.) o V. J. Calafell Ferrá (2006), Los convenios entre Comunidades Autónomas, Madrid: CEPC, págs. 69 y 70.

50 Con base en el art. 145.2 CE, así como en los respectivos preceptos de los Estatutos de Autonomía.

51 Así ya la jurisprudencia constitucional, por ejemplo, en la STC 132/1996.

52 Desde luego no sirven de parangón los convenios celebrados para la prestación de información o de asistencia técnica, personal, material o financiera, ni tampoco aquellos otros en los que las CC. AA. se coordinan para ejecutar obras públicas o prestar servicios.

53 Esto convenios fueron planteados como un mecanismo para instaurar una especie de nivel normativo interpuesto entre CC. AA. Véase V. J. Calafell Ferrá (2006: 366 y ss.).

54 Por cierto, no es preciso insistir en lo errado que es que los convenios afirmen que se otorga «validez» extraterritorial a la actuación de las CC. AA., cuando lo que se atribuye es eficacia extraterritorial.

55 Lo analizamos con base en la Ley 7/2010, de 29 de septiembre, por la que se aprueba el convenio por la Comunidad de La Rioja. Son también parte las CC. AA. de Cataluña, Andalucía, Comunidad Valenciana, Aragón, Castilla-La Mancha, Islas Baleares, Castilla y León. 
cualquiera de las CC. AA. signatarias «tendrá validez en el territorio de las demás ...».

b) El convenio sobre la conocida como licencia única interautonómica de caza y pesca ${ }^{56}$. La cláusula $4^{a}$ define la licencia como aquella que tiene «validez» en todas las CC. AA. signatarias. La cláusula 14a, bajo el epígrafe «Reconocimiento mutuo», establece que las CC. AA. «reconocen la validez de las licencias" para ejercer la caza y la pesca continental en su ámbito territorial. En consecuencia, los titulares «podrán ejercer su derecho» en el territorio de las CC. AA. signatarias, «respetando la legislación vigente en cada una de ellas» (en coherencia con la cláusula $3^{a}$, en la que se establece que el ejercicio de la actividad se rige por la normativa de cada territorio).

Fórmulas similares podrían plantearse en otras materias. Una podría ser la acreditación y evaluación de la calidad de las universidades ${ }^{57}$, materia en la que varias leyes autonómicas ${ }^{58}$ previeron el recurso a los convenios para articular el reconocimiento mutuo de acreditaciones ${ }^{59}$. Entiéndase esta opción en un contexto de creación de organismos autonómicos que, en algunos casos, han sido eliminados.

\subsection{Extraterritorialidad unilateral}

Un último tipo de extraterritorialidad es aquel en el que las situaciones jurídicas reconocidas administrativamente por una comunidad autónoma conforme a su propio ordenamiento ven ampliado su ámbito de vigencia a otras CC. AA. debido a la eficacia que les confiere directamente el ordenamiento de la primera. Aquí, la normativa estatal suele tener un papel limitado,

56 Convenio publicado en el BOE por Resolución de 6 de marzo de 2017, de la Dirección General de Desarrollo Rural y Política Forestal, por la que se publica el convenio de colaboración con las de Aragón, Principado de Asturias, Castilla y León, Extremadura, Comunidad de Madrid y Comunidad Valenciana.

57 En el sentido de la STC 107/2014 (FJ 6), que resuelve la vindicación competencial de Cataluña contra el Real Decreto 1052/2002, de 12 de octubre.

58 Así, el art. 12.1.k) Ley 5/2002, de 19 de junio, de la Generalidad Valenciana, de creación de la Comisión Valenciana de Acreditación y Evaluación de la Calidad en el Sistema Universitario Valenciano. En términos parecidos otras leyes luego derogadas, como la Ley 15/2002, de 27 de diciembre, de creación de la Agencia de Calidad, Acreditación y Prospectiva de las Universidades de Madrid (art. 6.3), y la Ley 2/2005, de 7 de abril, de la Agencia de Calidad Universitaria de Castilla-La Mancha (art. 5.3).

En la misma dirección, V. J. Calafell Ferrá (2006: 82). 
debido a la ausencia de un título competencial específico, sin perjuicio de la incidencia de las competencias ex arts. 1491.1, 13 o 18. Es la legislación autonómica la que de forma pormenorizada agota la regulación y, por supuesto, son las Administraciones de las CC. AA. las que aplican esa normativa.

Para exponer algún ejemplo, se nos permitirá que abordemos esta cuestión a partir del contexto normativo autonómico prexistente al ya citado Real Decreto 1056/2014, de 12 de diciembre, por el que se regulan las condiciones básicas de emisión y uso de la tarjeta de estacionamiento para personas con discapacidad. El motivo de hacerlo así se debe al modo en que algunas normas autonómicas, todavía vigentes, regularon el reconocimiento de las tarjetas otorgadas por otras CC. AA. Nuestras consideraciones deben entenderse, por tanto, abstracción hecha de la vigencia posterior del reglamento estatal.

Aquí cabe detectar dos modelos: a) el Decreto 256/2000, de 5 de diciembre, por el que se regula la tarjeta de estacionamiento para personas con discapacidad del País Vasco, dispone que la tarjeta concedida por los ayuntamientos «tendrá validez en el territorio de la Comunidad Autónoma», sin perjuicio de su utilización en todos los Estados miembros de la Unión Europea (art. 3) ${ }^{60}$. En definitiva, la comunidad regula la vigencia de sus permisos de forma unilateral y con proyección extraterritorial; y b) un caso distinto es el art. 2 del Decreto 97/2002, de 5 de marzo, sobre la tarjeta de aparcamiento de Cataluña ${ }^{61}$. A diferencia del ejemplo anterior, este precepto no otorga eficacia extraterritorial a las tarjetas otorgadas en Cataluña, sino que reconoce las otorgadas conforme a los modelos europeos concedidas por otras CC. AA. ${ }^{62}$.

Una primera cuestión que plantea este doble modelo es la «dirección de la unilateralidad», esto es, si puede ser prevista por la comunidad de origen ("ad extra»), o bien por la comunidad de destino ("ad intra»). Aparentemente, la primera opción parecía incompatible con el principio de territorialidad. No es constitucionalmente posible que una comunidad disponga la proyección de la eficacia de sus decisiones fuera de su territorio y hacia otras CC. AA., imponiendo unilateralmente la eficacia extraterritorial de actuaciones jurídico-administrativas sin que medie el reconocimiento o el compromiso voluntario de las CC. AA. de destino. Solo incorporando este último matiz

60 En sentido similar, el art. 3.3, Orden de 10 de marzo de 2010, sobre esta materia en Andalucía.

61 En otras materias se sigue ese modelo. Es el caso del art. 6.1, Decreto 198/2000, de 3 de octubre, por el que se aprueba el Reglamento de Pesca Marítima Recreativa del País Vasco, o del art. 71.6, Ley 7/2003, de 12 de noviembre, de Caza y Pesca Fluvial de la Región de Murcia.

62 Como curiosidad, el art. 3, Decreto 5/2018, de 16 de febrero, de La Rioja, ha refundido ambos modelos. 
puede ser admitido este modelo, algo que, como vamos a ver, asemejaría bastante las dos variantes de este tipo de extraterritorialidad.En otro caso la incostitucionalidad sería evidente. Esta conclusión ha sido la mantenida en varias ocasiones por el TC; en este sentido, recuérdese la anteriormente comentada STC $195 / 2001^{63}$.

¿Pueden alcanzarse conclusiones similares para el que denominamos como reconocimiento unilateral de efectos «ad intra»? La respuesta requiere alguna reflexión adicional. Se podría argumentar que si el principio de territorialidad constituye el límite espacial de validez y vigencia de las normas y actuaciones jurídico-administrativas de las CC. AA., entonces, la norma de una comunidad que previera unilateralmente la extensión de efectos de las normas y actuaciones jurídico-administrativas de otras CC. AA., estaría vulnerando el Estatuto de esas otras CC. AA. ${ }^{64}$. Sin embargo, la cuestión no parece que deba enfocarse así. Aquí la comunidad que otorga efectos extraterritoriales ad intra no es que realice una interpretación contraria al Estatuto de otras CC. AA. La clave está en que esa comunidad estaría restringiendo sus propias potestades para otorgar plena eficacia a las actuaciones dictadas por otras CC. AA. La eficacia a esas actuaciones autonómicas sería conferida como si las mismas hubieran sido dictadas por su propia Administración.

Esta conclusión nos lleva a otras dos cuestiones. La primera es una duda: ¿no implicaría esta fórmula una vulneración del principio de irrenunciabilidad de las competencias? No parece que esto sea correcto. En realidad, no se renuncia a ejercer las competencias propias, sino que se establece que el modo de ser ejercidas sea mediante el reconocimiento de actuaciones dictadas por otras CC. AA. Hay una limitación al ejercicio de potestades y a la aplicación del propio ordenamiento, pero no una renuncia a ordenar, controlar el reconocimiento e intervenir sobre esas situaciones.

63 Recuérdese que la STC 195/2001 (FJ 3) censura que una comunidad proyecte unilateralmente sus disposiciones y actos sobre otra, condicionando cómo esta ejerce sus competencias. En una línea similar pueden ser interpretadas las SSTC 72/1983 y 99/1986 (FJ 6). La misma opinión en A. Arce Janáriz (1989), «Normas sobre Derecho aplicable en la jurisprudencia del Tribunal Constitucional», Revista Española de Derecho Constitucional, 9, págs. 89-113 (págs. 105-107).

64 A ello habría que añadir que los Estatutos que han previsto excepciones al principio de territorialidad no prevén la extensión unilateral de efectos, ya que o bien confieren esa potestad al legislador estatal [art. 43.2 del Estatuto de Andalucía y art. 70.2 del Estatuto de Aragón, así como el art. 115 del Estatuto de Cataluña según la interpretación de la STC 31/2010 (FJ 63)], o bien se remiten a soluciones convencionales para lograr el mismo resultado. 
La segunda consideración se refiere al modo en que se articula el reconocimiento. En el supuesto analizado no existe imposición alguna de una comunidad frente a otra, sino libre asunción del modo en que se aborda la regulación y la actuación administrativa de esos asuntos. De hecho, lo habitual es que esta opción regulatoria quede condicionada normativamente por la reciprocidad en el reconocimiento. Es decir, esa fórmula normativa establece los mecanismos para manifestar expresamente el consentimiento en el reconocimiento.

\section{PARALELISMO CON EL RECONOCIMIENTO MUTUO}

\section{PLANTEAMIENTO DE LA CUESTIÓN}

Los tipos de extraterritorialidad expuestos nos acercan, con mayor o menor nitidez según el supuesto, a una realidad jurídica parecida, pero que tiene lugar en un escenario distinto: el de las relaciones jurídicas regidas por el principio de reconocimiento mutuo en el marco de la Unión Europea. Cada vez son más los ámbitos en los que el derecho europeo abandona una armonización pormenorizada, dejando paso a un modelo regulativo peculiar que articula el reconocimiento mutuo. Ese modelo es sin duda más respetuoso con el principio de subsidiariedad, en la medida en que no supone el desplazamiento de la normativa de los Estados miembros, sino su relación para ordenar y dotar de continuidad espacial a las relaciones jurídicas transnacionales.

Los supuestos de extraterritorialidad responden, en términos generales, a un modelo regulativo parecido. Es cierto que no puede decirse lo mismo y con idéntica intensidad en relación con los cuatro tipos identificados, pero sí que es evidente, al menos, en los supuestos de "extraterritorialidad horizontal» y se asemeja bastante en los casos de «extraterritorialidad convencional» e incluso «unilateral» ad intra. Aquí las conexiones entre ordenamientos autonómicos surgen por la acción legislativa del Estado (o de las propias CC. AA.) y la técnica es aparentemente similar: habilita la continuidad de las relaciones jurídicas que guardan conexiones territoriales con varias CC. AA., determinando la normativa autonómica aplicable y, en todo caso, la Administración autonómica competente para ejercer el control respectivo en cada fase de esas relaciones.

Para ratificar si la comparación realizada es certera, plantearemos a continuación un parangón entre los elementos que estructuran la articulación del reconocimiento mutuo y los que ordenan la extraterritorialidad en nuestro ordenamiento. La intención es, en definitiva, mostrar hasta qué punto podemos hablar de realidades jurídicas similares. 


\section{SOBRE EL RECONOCIMIENTO MUTUO EN EL DERECHO EUROPEO}

\subsection{Variantes del reconocimiento mutuo}

El art. 57.1 del Tratado de Roma de 1957 (actual art. 53.1 TFUE) estableció la facultad del Consejo para adoptar directivas con el fin de aplicar la regla de reconocimiento mutuo en materia de títulos y diplomas, así como respecto de las condiciones en las que habría de producirse el acceso y el ejercicio a ciertas profesiones. El recordatorio de este precepto permite abordar varios tópicos generados en torno al reconocimiento mutuo.

En primer lugar, su cita pone de relieve que la enunciación original del principio $^{65}$ no se debe a la STJCE de 20 de febrero de 1979 (Cassis de Dijon) ${ }^{66}$ como es habitual afirmar. Ahora bien, esto no quiere decir que no se deba reconocer la trascendencia fundamental de esta sentencia. En segundo lugar, aquel precepto también permite contraponer la disociación que de forma artificial ha mantenido alguna doctrina, entre armonización de legislaciones y reconocimiento mutuo. Si algo demostraba la literalidad del viejo art. 57 es la complementación in origine de ambos mecanismos. En la aceptación de esa complementariedad tuvo mucha más trascendencia la adopción por la Comisión Europea de la estrategia conocida como "Nuevo Enfoque ${ }^{67}$. Tanto es así, que la relevancia del «Nuevo Enfoque» ha llevado a inducir la creencia contraria, es decir, que el reconocimiento mutuo solo opera previa armonización. Esto, lógicamente, olvida que el principio se consolida con «Cassis de Dijon», precisamente, en ámbitos donde no existía una armonización de reglamentaciones técnicas. Cosa distinta es que esa armonización haya constituido un soporte determinante para lograr

65 Sin perjuicio del art. 220 TCEE, relativo al reconocimiento y la ejecución recíproca de las decisiones judiciales y extrajudiciales en materia civil. Otro precedente relevante fue el art. 100B AUE. Este precepto estableció el reconocimiento mutuo con efecto automático de las disposiciones nacionales no armonizadas, aunque no llegó a aplicarse dada la complejidad del análisis comparado que requería.

66 Las SSTJCE de 21 de junio de 1974 (C-2/74, Reyners) y de 3 de diciembre de 1974 (C-33/74, Binsbergen), antes que la Sentencia «Cassis de Dijon», proclamaron la necesidad de que las directivas a las que aludía el viejo art. 57 fueran aprobadas para conseguir la supresión de restricciones a la libre circulación. En ausencia de armonización, se ha aplicado con normalidad el reconocimiento mutuo: SSTJCE de 28 de abril de 1977 (C71/76, Thieffry), 15 de octubre de 1987 (C-222/86, Heylens), 7 de mayo de 1991 (C340/89, Vlassopoulou) o de 7 de mayo de 1992 (C-104/91, Aguirre Newman, S.A.).

67 Comunicación «Cassis de Dijon» (DOCE 3.10.1980 C 256) y White Paper 'Completing the Internal Market' (Milán, 28/29.6.1985) [COM (85) 310]. 
el cumplimiento del reconocimiento mutuo, así como que cada vez sean más los ámbitos con algún nivel de armonización. Por último, la afirmación anterior tampoco impide reconocer que, allí donde no existe una armonización sustantiva, se han establecido mecanismos armonizados para fomentar la efectividad del reconocimiento con la eliminación de barreras, basados en la comunicación de información ${ }^{68}$ y en el sistema de acreditación de los organismos de evaluación de la conformidad ${ }^{69}$. Todo esto significa, en definitiva, que la aplicación del reconocimiento mutuo puede tener lugar tanto en ámbitos no armonizados (el ejemplo de la Sentencia "Cassis de Dijon») ${ }^{70}$ como en otros previamente armonizados (eso sí, focalizando la armonización en contenidos variables), lo que avala la idea de modelos o variantes del reconocimiento mutuo ${ }^{71}$.

Una tercera consideración que nos recuerda el viejo art. 57 es que el reconocimiento mutuo opera en relación con todas las libertades comunitarias ${ }^{72}$. Esta obviedad nos permite poner de relieve que la formulación del reconocimiento mutuo presenta variables aplicativas que dependen, aparte de por la existencia o no de armonización, de la libertad concernida. En función de esos criterios, de forma general cabe diferenciar variantes que tienden hacia un reconocimiento automático, frente a otras de reconocimiento condicionado, dependiendo de la intensidad y alcance del control que ejerce la Administración del Estado de destino.

68 En ámbitos no armonizados, se optó por regular procedimientos de intercambio de información. Actualmente se regulan en el Reglamento 764/2008, de 9 de julio, por el que se establecen los procedimientos que los Estados miembros tienen que satisfacer cuando pretendan no aplicar el reconocimiento mutuo, en virtud de una norma técnica nacional, así como en la Directiva 2015/1535, de 9 de septiembre, por la que se establece un procedimiento de información en materia de reglamentaciones técnicas y de reglas relativas a los servicios de la sociedad de la información.

69 El Reglamento 764/2008 se complementa con el Reglamento 765/2008, de 9 de julio, relativo a los requisitos de acreditación y vigilancia del mercado, relativos a la comercialización de los productos.

70 Que esta posibilidad sigue siendo actual lo demuestra la STS 18 de julio de 2012 (Rec. 53/2008).

71 Ideas similares se deducen en L. de Lucía (2012), "Administrative Pluralism, Horizontal Cooperation and Transnational Administrative Acts», Review of European Administrative Law, 5(2), págs. 17-45 (págs. 21-22), y M. Guzmán Zapater (2001), «Un elemento federalizador para Europa: el reconocimiento mutuo en el ámbito del reconocimiento de decisiones judiciales», Revista de Derecho Comunitario Europeo, 10, págs. 405-438 (pág. 414).

72 En cualquier caso, y como es bien sabido, la aplicación del principio ha superado ese marco inicial, para constituirse en uno de los elementos estructurantes básicos del sistema jurídico europeo. 
Por último, otro aspecto que permite traer a colación la cita del Tratado de Roma es la variabilidad del nomen iuris utilizado en el derecho europeo desde entonces para referirse a una realidad jurídica similar. El recurso a denominaciones diversas alude a especialidades en la operatividad del reconocimiento, pero no a diferencias esenciales. Sin ánimo de exhaustividad, cabe citar las siguientes denominaciones, aparte de la específica de reconocimiento mutuo: $1^{\circ}$ ) En algunos casos se habla de «reconocimiento automático» y, además, se prevé o cabe deducir un «reconocimiento condicionado»"; $2^{\circ}$ ) Hay otros supuestos en los que se acude a la denominación de «reconocimiento recíproco", para designar al reconocimiento mutuo ${ }^{74} ; 3^{\circ}$ ) Por último, hay casos en los que las directivas europeas no califican al reconocimiento, es más, ni siquiera lo mencionan; a pesar de ello, esas normas incorporan un modelo regulativo similar. Este, que podemos calificar como «reconocimiento implícito», se puede identificar tanto en relación con la prestación de servicios ${ }^{75}$ como también, paradójicamente, en materia de libre circulación de mercancías ${ }^{76}$.

73 Así, por ejemplo, en la Directiva 2005/36, de 7 de septiembre, relativa al reconocimiento de cualificaciones profesionales. Véase, J. Agudo González (2015), «La Administración del reconocimiento mutuo», Revista de Administración Pública, 197, págs. 345-398. En relación con la Directiva precedente a la citada, la STS de 1 de julio de 2010 (Rec. 4177/2007) alude al reconocimiento mutuo con normalidad, a pesar de que esa directiva no se refiere expresamente, y con esos términos, al reconocimiento.

74 La Directiva 2006/126/CE, de 20 de diciembre, sobre el permiso de conducción, prevé el denominado "principio del reconocimiento recíproco», sin aludir al reconocimiento mutuo. Esto no ha sido impedimento para que las SSTJUE de 29 de abril de 2004 (C-476/2001) o de 29 de abril de 2004 (C-476/01, Kapper) afirmen que nos encontramos ante un supuesto de reconocimiento mutuo.

75 Caso de la Directiva 2006/123/CE, de 12 de diciembre, relativa a los servicios en el mercado interior. F. Jiménez García (2007), «Variaciones sobre el principio de reconocimiento mutuo y la Directiva 2006/123 en el marco de la libre prestación de servicios», Revista de Derecho Comunitario Europeo, 28, págs. 777-817 (pág. 805), y F. Jiménez García (2008), «La cooperación administrativa en la Directiva relativa a los servicios en el mercado interior», Revista de Derecho de la Unión Europea, 14, págs. 149-171 (pág. 158), E. Linde Paniagua (2008), «Libertad de establecimiento de los prestadores de servicios en la Directiva relativa a los servicios en el mercado interior», Revista de Derecho de la Unión Europea, 14, págs. 83-101 (pág. 92), o M. Domínguez Martín (2015), «Administrative Controls and Free Movement of Services within the Internal Market», en F. Velasco y F. Pastor (eds.), The Public Administration of the Internal Market, Groningen: Europa Law Publishing, págs. 71-89 (págs. 76 y ss.), analizan la Directiva como una expresión del reconocimiento mutuo.

76 No deja de ser llamativo que las directivas «Nuevo Enfoque» no aludan al reconocimiento mutuo, aunque es obvio que lo regulan. Las vigentes siguen el modelo 
A pesar de las variantes comentadas, lo cierto es que la configuración y aplicación del principio de reconocimiento mutuo es semejante desde su origen: los elementos que estructuran su configuración normativa y que gobiernan su aplicación son y han sido siempre los mismos ${ }^{77}$ : confianza mutua, equivalencia y país de origen. La discusión en torno a la equiparación del reconocimiento mutuo con el principio de equivalencia o con el del país de origen es, en realidad, $\operatorname{artificiosa}^{78}$, por cuanto cualquier variante del reconocimiento mutuo implica ambas vertientes, si bien con plasmaciones diferenciales en su peso relativo en función del supuesto. La mayor relevancia de una u otra vertiente tiene directa conexión con la noción de variantes del reconocimiento mutuo.

La equivalencia de legislaciones es el resultado de la confianza mutua y leal entre Estados miembros. A pesar de los vaivenes de la jurisprudencia europea y de algunas excepciones, parece razonable afirmar que la equivalencia es una premisa determinante del reconocimiento mutuo ${ }^{79}$. Equivalencia no significa total equiparación y tampoco presupone una correspondencia plena entre legislaciones. Equivalencia significa equiparabilidad, esto es, una correlación compartida de fines y objetivos, así como un nivel similar de protección ${ }^{80}$, sin que para ello

de la Decisión 768/2008/CE, de 9 de julio, que estableció el marco común para la comercialización de los productos. Todas disponen que, si los productos satisfacen las exigencias esenciales de las normas europeas, se procederá a su declaración como conformes, pudiendo circular por toda la Unión Europea. A tal efecto, el citado Reglamento 765/2008 establece el sistema de acreditación que garantiza la aceptación mutua del grado de competencia de los organismos de evaluación de la conformidad.

77 Véase J. Agudo González (2014), «La Administración del espacio administrativo europeo», Revista Vasca de Administración Pública, 99-100, págs. 111-159 (págs. 138 y ss.).

78 Las dudas planteadas acerca de la compatibilidad de ambos principios como elementos definitorios que se identificarían alternativa o excluyentemente con el reconocimiento mutuo, encuentran un soporte fundamental, aunque no único, tanto en la matizada jurisprudencia del TJCE/TJUE desde Cassis de Dijon en torno al grado de equivalencia exigible para admitir el reconocimiento mutuo, como en el modo en que la propuesta de Directiva de Servicios incorporó el principio del país de origen.

79 M. López Escudero (2000), «El mercado interior: cuestiones generales», en M. López Escudero y J. Martín (coords.), Derecho Comunitario Material, Madrid: McGraw Hill, págs. 28-41 (pág. 36). Aunque se discutió si la exigencia de equivalencia se podía deducir ya en Cassis de Dijon, desde la STJCE de 30 de septiembre de 1980 (Fietje, C-27/80) es evidente.

80 Así, tempranamente en «Completing the Internal Market: White Paper from the Commission to the European Council» (Milán, 28-29 junio 1985) (COM (85) 310). 
sea precisa una identidad de medios jurídicos ${ }^{81}$. El grado de equivalencia exigible es, y así se constata en la jurisprudencia, variable ${ }^{82}$. En líneas generales, está condicionado por la libertad comunitaria concernida ${ }^{83} \mathrm{y}$, sobre todo, por la existencia de armonización. En ausencia de armonización, la determinación de equivalencias también queda condicionada por los riesgos que se pretendan combatir ${ }^{84}$. En ámbitos armonizados, el grado de equivalencia dependerá tanto del objeto de esa armonización ${ }^{85}$ como de su grado de pormenorización ${ }^{86}$, pero sí que puede concluirse que, cuanto más pormenorizada sea la armonización, más fuerte será la presunción de equivalencia ${ }^{87}$.

81 En este sentido, M. Gardeñes Santiago (1999), La aplicación de la regla de reconocimiento mutuo y su incidencia en el comercio de mercancías y servicios en el ámbito comunitario e internacional, Madrid: Eurlex, pág. 86.

82 Una parte de la doctrina entiende que no es imprescindible una equivalencia estricta. Es el caso de R. García Pérez (2005), Libre circulación de mercancías y competencia desleal en la Comunidad Europea, Madrid-Barcelona-Buenos Aires: Marcial Pons, pág. 45. Para otros sí, como es el caso de M. López Escudero (1993), «La aplicación del principio del reconocimiento mutuo en el Derecho Comunitario", Gaceta Jurídica de la CE, D-19, págs. 119-165 (págs. 123-127). Coincidiendo con M. Gardeñes Santiago (1999: 88-90), la solución parece, sin embargo, casuística.

83 La clave estaría en la permanencia en otro Estado a que habilita cada libertad económica. Por ello, el TJCE/TJUE ha asumido una versión laxa del principio en materia de libre circulación de mercancías y de prestación de servicios, y más estricta en libre circulación de trabajadores y establecimiento (Sentencias de 12 de marzo de 1987, C-178/84, Comisión c. Alemania; de 5 de junio de 1997, as. C-105/94, máquinas de madera; de 28 de noviembre de 1986, as. 188/84; 15 de septiembre de 1994, C-293/93, Houtwiper; 25 de julio de 1991, C-76/90, Dennemayer; y de 28 de marzo de 1996, C-272/94). Esta afirmación se compadece bien con la evolución de la jurisprudencia que comentan para libre prestación de servicios A. L. Calvo Caravaca y J. Carrascosa González (2000), «Algunas cuestiones sobre la libre prestación de servicios en el Mercado Único Europeo», Noticias de la UE, 186, págs. 87-102 (pág. 88).

84 Para la libre circulación de mercancías, véase J. A. Gutiérrez Fons (2005), «Las cláusulas de reconocimiento mutuo: la perspectiva comunitaria del Derecho nacional», Revista Electrónica de Estudios Internacionales, 10, págs. 1-43 (pág. 21).

85 La casuística en libre circulación de mercancías, en J. A Gutiérrez Fons (2005: 22).

86 Es la diferencia entre la Directiva de Servicios y las directivas que armonizan determinados sectores como las citadas en el art. 2.2 de la Directiva, o bien como la Directiva 2000/12/CE, de 20 de marzo, relativa al acceso a la actividad de las entidades de crédito y a su ejercicio.

87 En una línea similar, M. Guzmán Zapater (2001: 416). 
La equivalencia entre legislaciones permite comparar los ordenamientos nacionales ${ }^{88}$ y seleccionar la norma aplicable a las distintas fases de las relaciones jurídicas entabladas con una potencial proyección transnacional. No estamos, por tanto, solo ante un problema de derecho material. El criterio de selección es el conocido como principio del país de origen. Según este criterio, el Estado de origen es el que ejerce el control inicial del cumplimiento de los criterios normativos exigidos por su propia legislación. Por su parte, el Estado de destino asume la carga de comparar el contenido normativo (lo que puede suceder cuando no existe armonización) y/o la aplicación al caso concreto (lo que suele acontecer en ámbitos no armonizados y es habitual en los armonizados), para decidir si reconoce los efectos generados por la legislación del Estado de origen plasmada en la oportuna actuación administrativa ${ }^{89}$.

La idea de selección de la norma aplicable incorpora dos efectos jurídicos que son en esencia conflictuales: $1^{\circ}$ ) admitir y reconocer la aplicación de la norma del país de origen y asumir la consecuencia jurídica; y $2^{\circ}$ ) no aplicar íntegramente la norma propia. A diferencia del derecho internacional privado, aquí la solución del conflicto no se concreta en la aplicación por el Estado de destino o de acogida de la norma del Estado de origen a un caso concreto $^{90}$, sino en admitir y considerar la aplicación de esa norma según fue llevada a cabo en origen, adquiriendo esa actuación eficacia transnacional.

88 En el espacio jurídico europeo concurren los presupuestos para garantizar la comparabilidad de las legislaciones y fomentar una presunción de equiparación. Véase A. von Bogdandy (2016), «La transformación del Derecho Europeo: El concepto reformado y su búsqueda de la comparación», Revista de Derecho Comunitario Europeo, 54, págs. 441-471 (págs. 447 y ss.).

89 En ausencia de equivalencia, no cabría la aplicación del reconocimiento mutuo, ya con base en la doctrina de las exigencias imperativas o del art. 36 TFUE, para los ámbitos no armonizados, ya en función del grado de armonización, con base en las excepciones previstas por las normas de derecho derivado.

90 Desde el derecho internacional privado se ha señalado que no tendría carácter «conflictual» porque solo exige la no aplicación de las normas del Estado de destino. En este sentido, M. Guzmán Zapater (1998), «El principio del reconocimiento mutuo: ¿un nuevo modelo para el Derecho Internacional Privado comunitario?», Revista de Derecho Comunitario Europeo, 3, págs. 137-170 (pág. 144), y M. Guzmán Zapater (2001: 417 y ss.). Otras opiniones lo interpretan como una norma «conflictual» singular: J. Basedow (1994), "Conflicts of Economic Regulation», American Journal of Comparative Law, 42(2), págs. 423-447 (pág. 447), o R. Michaels (2006), «EU Law as Private International Law? Re-Conceptualising the Country-Of-Origin Principle as Vested Rights Theory», ZERP Diskussionspapier, 5, págs. 1-45 (págs. 13 y ss.). 
En conclusión, con independencia de las divergencias doctrinales y de la evidente variabilidad de las expresiones del reconocimiento mutuo, no cabe negar que en todas ellas la equivalencia de legislaciones actúa como resultado de la confianza mutua entre Estados miembros, habilitando el reconocimiento de las normas y actuaciones del país de origen realizadas conforme a su ordenamiento ${ }^{91}$. Esto es, los elementos estructurantes del reconocimiento mutuo son unitarios y comunes, aunque variables en su plasmación jurídica, dando lugar a variantes del reconocimiento mutuo.

Sintetizando, puede llegarse a las siguientes formulaciones genéricas, sin duda alguna matizables: $1^{\text {a }}$ ) cuanto más amplia es la armonización sustantiva en un sector, mayor tendencia habrá a un reconocimiento automático; la clave se encuentra en la presunción de la equivalencia que forja la armonización y en que la responsabilidad del control recae fundamentalmente en la aplicación de la norma del país de origen; y $2^{\mathrm{a}}$ ) cuando no hay armonización o ésta es parcial, el reconocimiento tiende a estar condicionado, de modo que la equivalencia solo puede presumirse de forma parcial o limitada; por ello, el país de destino o de acogida ha de ostentar facultades de control para verificar aquella equivalencia al reconocer la actuación del país de origen.

2.2. Apunte sobre el principio de reconocimiento mutuo como principio ordenador de una Administración funcionalmente integrada

La programación normativa de las Administraciones nacionales en materia de reconocimiento mutuo también pone de relieve la función relacional o conectiva que le caracteriza. Aquí se ponen en relación: 10) la aplicación de la normativa por la Administración del Estado de origen en un caso concreto; con $2^{\circ}$ ) la no aplicación plena de una normativa equivalente en el Estado de destino y el consecuente reconocimiento de la situación jurídica nacida en el país de origen, otorgándole una eficacia similar a la que podría haber declarado la Administración de acogida conforme a su ordenamiento ${ }^{92}$. Por tanto, una consecuencia lógica de la programación formal derivada del principio de reconocimiento mutuo es la articulación de la actividad administrativa mediante un iter procesal complejo y transnacional que ordena la «división del trabajo» o el reparto de funciones entre administraciones nacionales ${ }^{33}$.

Desde este punto de vista relacional, podría decirse que el reconocimiento mutuo permite «nivelar» la divergencia existente entre la única tarea admi-

\footnotetext{
91 Una visión integradora similar, ya en M. Guzmán Zapater (2001: 416).

92 Sobre estas cuestiones, véase J. Agudo González (2014 y 2015).

93 Véase, al respecto, L. de Lucia (2009), Amministrazione transnazionale e ordinamento europeo, Turín: Giappichelli, págs. 21 y ss.
} 
nistrativa a llevar a cabo (reconocer el ejercicio de un derecho o una facultad y el acceso a un mercado) y la diversidad de competencias administrativas de las administraciones nacionales condicionadas por el principio de territorialidad. El reconocimiento mutuo nivela en un único iter procesal el ejercicio de competencias administrativas diversas en dos ámbitos nacionales distintos, con la existencia de una única «tarea administrativa». Esa nivelación competencias/ tareas permite describir la actuación administrativa como un continuo funcional (procedimiento complejo integrado funcionalmente).

¿Cómo se articula más específicamente ese proceso? La premisa fundamental es que las administraciones involucradas actúan con base en criterios cooperativos. Con independencia de las variantes del reconocimiento, de forma sintética podría decirse que la estructura operativa sería la siguiente: a) la Administración del país de origen dicta $\operatorname{actos}^{94}$ conforme a su propio ordenamiento que, potencialmente, tienen eficacia transnacional; b) la eficacia transnacional de las disposiciones y de los actos del Estado de la Administración de origen se articula mediante la solicitud de reconocimiento ante la Administración del Estado de destino o de acogida. Esto significa que el reconocimiento mutuo habilita al sujeto titular de esos derechos a la elección del derecho aplicable y de la Administración competente para reconocer el ejercicio de las libertades comunitarias que, desde luego, no tienen por qué coincidir con la de su nacionalidad ${ }^{95}$; c) la solicitud de reconocimiento es resuelta por la Administración de destino; el principio de reconocimiento mutuo prohíbe que esta actuación sea reproductora de la precedente en origen. Las funciones de la Administración del Estado de destino serán variables y, en función del condicionamiento del reconocimiento (automático versus condicionado), se concretarán en una serie modulada de facultades (verificar documentalmente y/o, en su caso, imponer medidas compensatorias, o bien autorizar...), siempre condicionada por el respeto del principio de proporcionalidad; por lo que se refiere a la Administración de origen, una vez solicitado el reconocimiento, su actuación es fundamentalmente de asistencia informativa; y d) la resolución que pone fin al procedimiento de reconocimiento podrá ser variable en

94 Para ser exactos habría que hablar genéricamente de actuaciones relevantes jurídicamente, pues esa actuación con potenciales efectos transnacionales no tiene por qué concretarse en un acto administrativo, sino que puede plasmarse en un certificado u otra actuación similar y, es más, incluso puede ser dictada por una entidad privada acreditada.

95 La autonomía de la voluntad se alza como elemento determinante en la selección y aplicación del derecho: M. Gnes (2004), La Scelta del Diritto. Concorrenza tra ordinamenti, arbitraggi, diritto comune Europeo, Milán: Giuffrè, pág. 459, o J. Agudo González (2014: 375 y ss.). 
su contenido, pero en todo caso estará dirigida a reconocer plena eficacia a las normas y actuaciones jurídicas dictadas en el país de origen. Esa resolución no es sustitutiva de la dictada en origen, sino complementaria de esta, habilitando su plena eficacia transnacional ${ }^{96}$.

\section{ENCAJE CONSTITUCIONAL DEL RECONOCIMIENTO MUTUO COMO FÓRMULA PARA ARTICULAR LA EXTRATERRITORIALIDAD}

\section{PLANTEAMIENTO DE LA CUESTIÓN}

En este último apartado proponemos analizar si los tipos de extraterritorialidad identificados en la primera parte de este estudio se basan en un modelo regulativo similar al que define al reconocimiento mutuo. En términos generales, se puede afirmar que este parangón no es irrazonable. Por un lado, la equivalencia entre ordenamientos autonómicos constituye una condición que se presume gracias a la labor armonizadora tácita o expresa que cumplen el bloque de la constitucionalidad, la legislación estatal y el derecho europeo. Si en el «espacio jurídico europeo» cabe hablar de confianza mutua y de equivalencias entre los distintos ordenamientos jurídicos nacionales, cuanto más se podrá decir de un ordenamiento unitario como el de cualquier Estado federado o descentralizado ${ }^{97}$. Por otra parte, la aplicación del ordenamiento de origen en el acceso a una actividad y el reconocimiento posterior por la Administración de destino o de acogida es algo relativamente común en nuestro ordenamiento. Y lo es, no solamente por mor del derecho europeo, sino también, como mostramos en su momento, en virtud de múltiples ejemplos normativos que nada tienen que ver con la ejecución de normas europeas. En todos esos ejemplos se recordará que el legislador ha seleccionado puntos de conexión determinantes de la comunidad autónoma competente, coincidiendo con la idea genérica de país de origen. Recuérdese que esos puntos de

96 M. Gardeñes Santiago (1999: 178) o X. Arzoz Santiesteban (2002: 17 y 18). Sobre los actos con eficacia transnacional, véanse R. Bocanegra y J. García Luengo (2008), «Los Actos Administrativos Transnacionales», Revista de Administración Pública, 177, págs. 9-29, y J. Ortega Bernardo (2017), «El acto administrativo transnacional en el Derecho Europeo del mercado interior", Revista Española de Derecho Administrativo, 188, págs. 81-124. La clave es que los tipos de actos transnacionales se corresponden con los tipos de reconocimiento mutuo que identifican G. Vesperini (2011), Il vincolo europeo sui diritti amministrativi nazionali, Milán: Giuffrè, págs. 29-52, o L. de Lucia (2012: 24 y ss.): automático y condicionado.

97 A. von Bogdandy (2016: 469). 
conexión tienen concreciones distintas, pero, como regla general, designan como entidad territorial competente a la del territorio de origen, esto es, a aquella en que la persona física o jurídica accede, pone en marcha, constituye o adquiere determinadas facultades cuyo reconocimiento solicita o promueve ante su Administración ${ }^{98}$.

Este parangón inicial no puede servir para dejar de poner de relieve que no todo tipo de extraterritorialidad encaja con la misma solvencia en los moldes básicos del reconocimiento mutuo. El modelo regulativo que articula el reconocimiento mutuo puede ser calificado como un modelo «relacional», en cuanto que articula los mecanismos gracias a los cuales se resuelven las relaciones entre ordenamientos de los Estados miembros, otorgando eficacia a las normas y/o a las actuaciones jurídico-administrativas de otros Estados, habilitando de este modo la continuidad o extensión de su vigencia más allá de las fronteras de cada Estado. La articulación del reconocimiento mutuo, por tanto, se combina, en su manifestación original, con una descentralización regulativa que supone el mantenimiento de cierta diversidad material entre ordenamientos nacionales. Dicho de otra manera, cuanto más centralizada se encuentra la ordenación de una materia en las instituciones comunitarias (no necesariamente en materias exclusivas, sino también compartidas con recurso a reglamentos pormenorizados), más se difumina y pierde sentido hablar de un modelo regulativo que articula el reconocimiento mutuo.

El traslado de estas conclusiones a la tipología de supuestos de extraterritorialidad identificados en nuestro ordenamiento interno nos permite intuir consecuencias diversas; mientras que algunos casos no se acoplan bien a los moldes del reconocimiento mutuo, otros parecen ajustarse perfectamente a la noción de variantes del reconocimiento: a) podríamos decir que, debido a la ausencia de armonización legislativa estatal en los supuestos de «extraterritorialidad unilateral» (ad intra), la relación entre ordenamientos autonómicos se sometería a un reconocimiento que, calificado en muchos casos de recíproco, evoca una exigencia de equivalencia alta que se concretaría en mecanismos de reconocimiento condicionado; b) en los supuestos de «extraterritorialidad convencional», la labor de adaptación común de su normativa que, motu proprio asumen las CC. AA., permite presumir la equivalencia entre ordenamientos y, por ello, recurrir a fórmulas de reconocimiento tendencialmente

98 Como parangón merece la pena la STC 173/2005 (FJ 10) en la que se analizan los puntos de conexión establecidos por el legislador estatal a los efectos de poner en marcha el principio de autorización única en materia de seguros. La Sentencia compara la Directiva en la materia y la Ley, llegando a la conclusión de que existe una identidad evidente entre país de origen y domicilio de la entidad aseguradora. 
automático; y c) en los casos de «extraterritorialidad horizontal», donde la armonización es a lo sumo parcial, se ha de otorgar un mayor peso a la equivalencia entre normativas autonómicas, de modo que se deduce una tendencia a un reconocimiento condicionado, aunque el grado de condicionalidad dependerá del estado de la armonización.

Respecto a los supuestos de "extraterritorialidad plena», el escenario es distinto. Aquí, como la legislación estatal ordena sustantivamente la materia, se garantiza una ordenación homogénea y también que la decisión tomada por la comunidad de origen tenga eficacia automática en toda Espańa. Tanto la centralización de la ordenación sustantiva como la total automaticidad de la eficacia extraterritorial de los actos de las CC. AA., dificultan identificar un modelo de regulación que incorpore mecanismos de reconocimiento mutuo en sentido estricto.

Esta relativa adecuación entre supuestos de extraterritorialidad y variantes de reconocimiento mutuo que pudiera derivarse de la aproximación precedente, ha encontrado una dura contestación en la STC 79/2017, dictada en el recurso de inconstitucionalidad interpuesto contra la LGUM ${ }^{99}$. Los próximos apartados estarán dedicados a realizar un análisis crítico de los argumentos de la sentencia, así como a proponer soluciones alternativas.

\section{LA DOCTRINA DE LA STC 79/2017}

Los términos que emplea la STC 79/2017 para rechazar la equiparación entre el reconocimiento mutuo y el principio de eficacia nacional establecido en la LGUM, que habilitaba la extraterritorialidad de las disposiciones y actos administrativos de las CCAA, no pueden ser compartidos íntegramente. Las reflexiones de la sentencia sobre ese principio parten de lo que el TC califica como «situar la cuestión discutida en su contexto» (FJ 12). La intención del Tribunal no es otra que hacer un parangón con las respuestas que ha dado «el legislador estatal a la existencia de una pluralidad regulatoria con aquellas otras que, con la misma finalidad, atenuar aquella pluralidad, se han experi-

99 La STC 79/2017 declara que el principio de eficacia de las actuaciones de las autoridades competentes en todo el territorio nacional es inconstitucional por exceder de la competencia estatal ex art. 149.1.13 y por vulnerar el principio de territorialidad. La sentencia no anula el art. 6 donde se formula el principio, sino los arts. 18.2. b), c) y e), 19 y 20 de la Ley, así como la disposición adicional 10ª que sustentan su redacción en el citado principio o son consecuencia directa del mismo. La inconstitucionalidad del art. 6 fue declarada finalmente por STC 110/2017. El juicio de constitucionalidad de la LGUM culmina con las SSTC 111 y 119/2017, ambas condicionadas por la previa STC 79/2017. 
mentado con anterioridad en el ordenamiento europeo y en nuestro propio ordenamiento nacional». Entre esos «instrumentos», incluye al reconocimiento mutuo.

El enfoque que asume el tribunal es un tanto equívoco. La sentencia realiza un análisis del reconocimiento mutuo a partir de una (y solamente una) de sus variantes: la que tiene lugar en el marco de la libre circulación de mercancías (y, por extensión, de la libre prestación de servicios) en ámbitos no armonizados. Para armar su análisis, se cita la Sentencia Cassis de Dijon y algún otro precedente ${ }^{100}$. Con base en ese soporte jurisprudencial, sintetiza la configuración pretoriana del reconocimiento mutuo del siguiente modo:

Se reconoce, por tanto, un principio de reconocimiento mutuo condicionado, pues el presupuesto para su aplicación efectiva es la equivalencia en el nivel de protección, pues de no concurrir tal equivalencia, y en ausencia de una normativa armonizadora europea que establezca un nivel común de protección, cabría que los Estados miembros justificasen la aplicación de un estándar propio en la necesidad de promover legítimos objetivos.

$Y$ ańade que el reconocimiento mutuo

supone que, en relación con los bienes, un Estado miembro debe permitir la comercialización en su territorio de los bienes elaborados de conformidad con las reglamentaciones del Estado de origen, cuando los productos importados han sido fabricados conforme a unos parámetros que establecen un nivel de protección similar. Ahora bien, cuando no se cumple el presupuesto de que el nivel de protección sea equivalente, los Estados miembros sí podrán imponer el cumplimiento de su nivel de protección a los bienes elaborados conforme a estándares de protección inferiores.

El punto de partida que asume el tribunal condiciona el resto de sus argumentos. Partiendo de una variante del reconocimiento mutuo en ámbitos no armonizados, centra lógicamente su atención en la existencia de equivalencias entre ordenamientos. No hace falta decir que este punto de arranque es discutible porque la sentencia omite la normalización actual del reconocimiento mutuo en ámbitos armonizados ${ }^{101}$. Por otro lado, también es discutible porque, siendo que la sentencia expone cómo funciona el reconocimiento mutuo

100 Las SSTJCE de 28 de enero de 1986 (C-188/84, Comisión c. Francia) y de 22 de enero de 2002 (C-390/99, Canal Satélite Digital, S.L.). Eso es todo.

101 A pesar de que el Tribunal ya había intervenido en procesos en los que el reconocimiento mutuo operaba en ámbitos armonizados: SSTC 244/1993 (FJ 3.B), 235/1999 (FJ 1) o 173/2005 (FJ 10). 
en materias sin armonización, lo paradójico es que centre buena parte de sus esfuerzos en justificar el reconocimiento en ámbitos armonizados y que, sin embargo, no reflexione abiertamente sobre la eventual constitucionalidad del reconocimiento mutuo en ámbitos no armonizados por el legislador estatal ${ }^{102}$. Esta crítica tiene todo el sentido, si tenemos en cuenta los reiterados alegatos del tribunal considerando que la LGUM no es una norma armonizadora ${ }^{103}$.

Lo que sí hace la sentencia es insistir en las soluciones jurídicas existentes en nuestro ordenamiento que considera equiparables al reconocimiento mutuo. Centrada en la prexistencia de equivalencias, las encuentra allí donde hay armonización, esto es, en los supuestos de «extraterritorialidad plena» ${ }^{104}$ en los que, sin embargo, ya lo hemos dicho, se difumina bastante la idea de reconocimiento mutuo: "[...] este TC se ha referido en alguna ocasión al razonable reconocimiento de la eficacia extraterritorial o supracomunitaria de determinadas acciones efectuada por las Administraciones autonómicas cuando se trataba de supuestos de actuación ejecutiva autonómica que aplicaban un estándar equivalente recogido en una norma estatal». En estos casos, se admite el reconocimiento de eficacia extraterritorial (FJ 12.a): «En la medida en que exista una normativa de la Unión Europea armonizada o una legislación estatal común, o exista una pluralidad de legislaciones autonómicas que, no obstante sus posibles diferencias técnicas o metodológicas, fijen un estándar que pueda ser considerado equivalente, el Estado podrá reconocer a las decisiones autonómicas efectos extraterritoriales a través de la imposición del reconocimiento de la decisión adoptada en una determinada Comunidad Autónoma en el resto». $\mathrm{Y}$ ańade: «El principio de reconocimiento mutuo consiente el reconocimiento de eficacia extraterritorial de los actos y disposiciones de un determinado poder territorial; pero deja subsistente la capacidad de los pode-

102 Con anterioridad a la sentencia, E. Linde Paniagua (2008: 93) y G. Fernández Farreres (2014), «Unidad de mercado y libertades de empresa y de circulación de bienes en la Ley 20/2013, de 9 de diciembre», Revista Española de Derecho Administrativo, 163, págs. 109-144, se pronunciaron sobre este extremo optando por una posición similar a la del Tribunal Constitucional. No obstante, G. Fernández Farreres parecía admitir esa posibilidad, siempre y cuando la pluralidad de normas autonómicas tuviera un contenido idéntico.

103 No hace falta decir que esa omisión también genera la duda acerca de la constitucionalidad de los ejemplos existentes en nuestro ordenamiento en los que, sin armonización previa, podemos hablar de regulaciones equivalentes y de reconocimiento mutuo entre CC. AA. (extraterritorialidad «convencional» y «unilateral»).

104 Todas las sentencias citadas (SSTC 87/1985, 100/1991 y 236/1991) confirman que el tribunal se está refiriendo a los supuestos que aquí hemos calificado como «extraterritorialidad plena». 
res territoriales de poder establecer, en ausencia de armonización centralizada, un nivel de protección propio y distinto».

La argumentación es confusa. Se parte de una exposición general del reconocimiento mutuo en ámbitos no armonizados, para luego admitir su aplicación justamente allí donde hay una previa armonización que garantice la existencia de equivalencias entre los ordenamientos de las CC. AA. Pero aún más, de las palabras recién transcritas tampoco queda claro si el Tribunal Constitucional rechaza definitivamente la constitucionalidad del reconocimiento mutuo en ámbitos no armonizados por el legislador estatal.

La sentencia aquí «juega al despiste». En el párrafo final recién transcrito, el tribunal parece admitir que el reconocimiento de eficacia extraterritorial puede operar con o sin previa armonización. En un sentido similar se pronuncia la sentencia (FJ 13.a) cuando analiza la vulneración del principio de territorialidad:

[...] el reconocimiento por parte del Estado de efectos supraautonómicos a las actuaciones autonómicas tiene, en principio, un límite claro: la imposibilidad de reconocer tales efectos cuando no existe una equivalencia en las normativas aplicables. En la medida en que exista una legislación estatal común, o exista una pluralidad de legislaciones autonómicas que, no obstante sus diferencias técnicas o metodológicas, fijen un estándar que pueda ser considerado equivalente, el Estado podrá reconocer a las decisiones ejecutivas autonómicas efectos extraterritoriales a través de la imposición del reconocimiento de la decisión adoptada en una determinada Comunidad Autónoma en el resto. Así lo habría reconocido nuestra doctrina en relación con las actuaciones autonómicas de carácter ejecutivo.

Obsérvese que, del inciso transcrito, podría deducirse que el TC presume que la eficacia extraterritorial requiere, o bien «una legislación estatal común» (armonización), o bien «una pluralidad de legislaciones autonómicas que, no obstante sus diferencias técnicas o metodológicas, fijen un estándar que pueda ser considerado equivalente» (ausencia de armonización). Sin embargo, esta conclusión no parece definitiva. Cuando se concreta en ejemplos, se observa que todos son supuestos de «extraterritorialidad plena» ${ }^{105}$. En fin, la sentencia nos devuelve a un escenario de armonización sustantiva centralizada en el legislador estatal. Esto explicaría que, como la LGUM no es considerada por el tribunal una norma armonizadora, no pueda prever el reconocimiento de la extraterritorialidad de los actos y disposiciones de las CC. AA.

Ya que como a la sentencia aparentemente solo le interesa el reconocimiento de eficacia extraterritorial previa armonización estatal, otra cuestión

$\overline{105}$ Cita las SSTC 243/1994, 175/1999, 126/2002, 14/2004 y 33/2005. 
que suscita este planteamiento es el que tiene que ver con el grado o tipo de armonización que se requiere. La sentencia se refiere a ello cuando aborda el que denomina «segundo instrumento» válido para «mitigar algunas de las consecuencias de la existencia de una pluralidad regulatoria fundada en la legítima capacidad territorial de adoptar políticas propias» (FJ 12.b), refiriéndose al recurso a los títulos competenciales horizontales del Estado.

La primera impresión es que este «instrumento» es alternativo al reconocimiento mutuo. Sin embargo, no se puede admitir que el tribunal quiera decir algo así. Resultaría inaceptable afirmar que los «estándares comunes» o el «común denominador normativo» establecido con base en los arts. 149.1.1, 13 o 18, no genere un efecto armonizador que pudiera servir de base al reconocimiento mutuo, siempre y cuando se establezcan equivalencias suficientes entre ordenamientos autonómicos. En este sentido, y conjuntamente con ese efecto armonizador, la sentencia (FJ 13.a) afirma que «los títulos competenciales reconocidos en los artículos 149.1.13 y 149.1.18 CE habilitan al Estado para coordinar las normativas y las actuaciones administrativas territoriales autonómicas mediante el establecimiento de un mecanismo como es el de reconocimiento de eficacia de las actuaciones autonómicas en el resto del territorio nacional» ${ }^{106}$. Específicamente, califica al «reconocimiento de eficacia de las actuaciones autonómicas en el resto del territorio nacional», como «una manifestación específica del principio de coordinación» (FJ 13.a). En fin, estos títulos horizontales también parecen adecuados para habilitar el reconocimiento de efectos extraterritoriales, a pesar de que no exista una armonización plena.

¿Cuál es, entonces, la inconstitucionalidad que se imputa a la LGUM, habiendo sido dictada con base en esos títulos competenciales? Centrado el peso de la argumentación en la inexistencia de una previa equivalencia, la sentencia entiende que la LGUM no solo no es una norma armonizadora ${ }^{107}$, sino que, además, prácticamente limita su contenido a habilitar de forma general ${ }^{108} \mathrm{y}$ au-

106 La STC 79/2017 (FJ 3) sintetiza una reiterada doctrina constitucional que ha mantenido que el Estado goza de facultades de coordinación de las CC. AA. en aquellas materias en las que posee un título competencial específico (SSTC 32/1983, 144/1985, $102 / 1995$ o $86 / 2014)$.

107 Esto es reiterado en varias ocasiones: «La Ley 20/2013 renuncia a fijar por sí misma unas normas armonizadas (...). No existe entonces finalidad armonizadora alguna...» (FJ 13.b).

108 A esto alude la Sentencia (FJ 13.b) al afirmar que el «menoscabo» que provoca la LGUM es mayor porque «es una disposición que opera transversalmente sobre variadas competencias autonómicas; es una disposición concebida para ser aplicada a toda actividad económica y producto...». 
tomática que la normativa de la comunidad de origen sea aplicada y reconocida por la de destino, sin que exista garantía de que los niveles de protección establecidos sean equivalentes. Es decir, establece un mecanismo de coordinación que habilita el reconocimiento de eficacia extraterritorial sin garantizar, con una armonización mínima, la equivalencia entre normas autonómicas ${ }^{109}$. Conclusión: el principio de eficacia nacional constituye una suerte de «suplantación» de ordenamientos, dictada yendo más allá de lo que habilita el art. 149.1.13, que incurre en una vulneración del principio de territorialidad ${ }^{110}$ Sin embargo, el TC no ahonda en las consecuencias que podrían derivarse de este enfoque.

\section{ANÁLISIS CRÍTICO}

La STC 79/2017 plantea bastantes interrogantes. Probablemente el más importante tiene que ver con el grado de satisfacción con que la doctrina del Tribunal sirve para lograr los objetivos que orientan la sentencia. Vayamos por partes.

Detrás de la inconstitucionalidad de la LGUM se centra, sintéticamente, la salvaguarda de la autonomía territorial y de las competencias de las CC. AA., subrepticiamente abrogadas, con extralimitación competencial, mediante la implementación de un mecanismo de reconocimiento automático de la eficacia

109 La STC 79/2007 señala que el reconocimiento mutuo permite condicionar la prestación de servicios y la comercialización de bienes «a la existencia de una equivalencia en el nivel de protección de las diversas normativas territoriales, extremo ausente en la regulación del principio de eficacia nacional», en el que «la autoridad de destino ha de asumir la plena validez de lo establecido por la autoridad de origen tanto en materia de requisitos de acceso a la actividad como en relación con la circulación de bienes, sin que ese reconocimiento venga condicionado por la existencia de equivalencia alguna» (FJ 12.c).

${ }^{110}$ La sentencia afirma que el principio de eficacia nacional (FJ 13.a) «supone obligar a una Comunidad Autónoma a tener que aceptar dentro de su territorio una pluralidad de políticas ajenas (...) y entraña la constricción de su autonomía al permitirse la aplicación en el territorio de la Comunidad Autónoma de disposiciones adoptadas por un órgano representativo en el que los ciudadanos de la Comunidad Autónoma en la que finalmente se aplica no se encuentran representados». Y ańade que con ello (FJ 13.b) «el sistema de distribución de competencias queda alterado sustancialmente»o que «la competencia queda vaciada de contenido...». G. Fernández Farreres (2014), M. J. Alonso Mas (2014), «La eficacia de los títulos habilitantes en todo el territorio nacional y la aplicación de la regla del lugar de origen», en M. J. Alonso Mas (dir.), El nuevo marco jurídico de la unidad de mercado, Madrid: La Ley, págs. 293-353, o M. Carlón Ruiz (2014), «Los mecanismos de protección de la Ley de unidad de mercado en el seno de la Ley 20/2013», Revista Española de Derecho Administrativo, 165, págs. 147-182, ya habían llegado a una conclusión parecida. 
extraterritorial de las actuaciones jurídico-administrativas de las CC. AA. que vulnera el principio de territorialidad que define al Estado autonómico.

La rigurosidad del Tribunal en este punto choca con el tratamiento que hace de los preceptos de la LGUM que limitan las facultades de las CC. AA. para establecer disposiciones orientadas a salvaguardar bienes jurídicos o intereses con relevancia particular en un territorio determinado (arts. 5 y 17). A juicio de la mayoría de la doctrina, esos preceptos inciden de forma desproporcionada en las competencias autonómicas ${ }^{111}$. Sin embargo, el TC ratifica su constitucionalidad ${ }^{112}$.

Se hace esta consideración porque con ese doble rasero el tribunal nos traslada el siguiente parámetro de control: a) el Estado, sin armonización previa, no puede establecer que los actos y disposiciones de las CC. AA. gocen de efectos extraterritoriales porque, en el entender del tribunal, vulnera el principio de territorialidad; y, por otro lado, b) el Estado ostenta competencias (fundamentalmente, el art. 149.1.13) para limitar tajantemente las facultades de las CC. AA. para establecer políticas propias en materias de sus competencias. Es decir, el tribunal se preocupa por garantizar que sin armonización previa las CC. AA. puedan establecer regímenes jurídicos con niveles de protección divergente, pero al mismo tiempo dedica la misma intensidad para cercenar las competencias autonómicas, precisamente, para poder establecer esos distintos niveles de regulación y protección.

111 S. Muñoz Machado (2014), «Sobre el restablecimiento legal de la unidad de mercado", Revista Española de Derecho Administrativo, 163, págs. 11-22; C. Padrós Reig y J. M. Macías Castaño (2014), "Los instrumentos administrativos de garantía de la unidad de mercado», Revista de Administración Pública, 194, págs. 113-151, pág. 123; J. Agudo González (2015: 391 y ss.) y J. Sola Teyssiere (2016), «El principio de eficacia nacional de los medios de intervención de acceso a las actividades económicas», Revista Española de Derecho Administrativo, 179, págs. 211-250. La crítica más rotunda en M. Rebollo Puig (2014), "La libertad de empresa tras la ley de garantía de la unidad de mercado», Revista Española de Derecho Administrativo, 163, págs. 23-33, y M. Rebollo Puig (2015), «El Estado Autonómico tras la Ley de Garantía de la Unidad de Mercado y sus principios de necesidad y eficacia nacional», Revista Andaluza de Administración Pública, 91, págs. 91-146, así como en el voto particular de E. Alonso García al Dictamen del Consejo de Estado nº 631/2013 sobre el anteproyecto de LGUM.

112 Muy sintéticamente, para el TC (FJ 4.b) y FJ 7.a) b), el art. 149.1.13 habilita al Estado para condicionar los fines de la acción pública autonómica, mediante la proscripción de fines concretos o con la determinación del propio fin en un sector preciso. En el presente caso entiende que no se restringen en exceso las competencias de las CC. AA. Un ejemplo de las consecuencias de ambos artículos, en la STC 89/2017 (FJ 1113), en relación con el art. 18 de la Ley 20/2010, de 7 de julio, del cine de Cataluña. 
Este resultado desconcertante tiene mucho que ver con el enfoque que asume el tribunal para enjuiciar la LGUM. El tribunal podría haber asumido dos enfoques:

10) Afrontar el análisis del principio de eficacia nacional desde la vertiente de la constatación de equivalencias entre ordenamientos autonómicos. Esta es la opción obvia que asume la sentencia y, por ello, incide una y otra vez en la ausencia de armonización que se imputa a la LGUM. $\mathrm{El}$ argumento es sencillo, aunque erróneo: si no hay equivalencias establecidas previa armonización a nivel estatal no cabe reconocimiento de efectos extraterritoriales. Esto, desde luego, nada tiene que ver ni con el planteamiento inicial de la sentencia (recuérdese que explica el origen del reconocimiento mutuo en ámbito nos armonizados), ni con la realidad del derecho europeo, pero tampoco con la de nuestro ordenamiento.

Tanto el enfoque adoptado como la conclusión alcanzada están orientados a un objetivo: salvaguardar las competencias de las CC. AA. que, en el entendimiento del tribunal, se verían desplazadas por mor de la eficacia extraterritorial de las disposiciones y actos de otras CC. AA., no necesariamente equivalentes, que habilita el principio de eficacia nacional. Esta forma de proceder resulta paradójica porque, muy al contrario de lo que parece expresar el tribunal, fortalece la competencia estatal por una doble vía ${ }^{113}$ : a) fomenta la armonización y la generación de equivalencias, consolidando la idea de que el establecimiento del reconocimiento de eficacia extraterritorial solo es posible cuando el Estado armoniza una materia; y b) reconoce que el Estado ostenta competencias para restringir de forma determinante el alcance y contenido de las competencias autonómicas, limitando la diversidad entre CC. AA. ${ }^{114}$.

2o) Acometer el análisis desde la vertiente de la automaticidad del principio de origen. El TC asume indirectamente este planteamiento, en la medida en que lo imputa a la implementación del principio de eficacia nacional.

113 Cuando fue aprobada la LGUM, buena parte de la doctrina consideró que la Ley produciría una homogeneización de los ordenamientos autonómicos contraria a la Constitución. En este sentido, J. Tornos Mas (2014), «La Ley 20/2013, de 9 de diciembre de garantía de la unidad de mercado", Revista de Estudios Autonómicos y Federales, 19, págs. 144-177 (pág. 157); G. Fernández Farreres (2014); M. Carlón Ruiz (2014). Visto el resultado que genera la STC 79/2017, ¿no será necesario volver a utilizar la misma crítica?

114 Todo ello, además, sin perjuicio de acudir a las leyes de armonización del art. 150.3 CE, como así sugiriera J. Tornos Mas (2014: 169 y ss.). 
Por ello, declara inconstitucionales los arts. 18.2. b), c) y e), 19, 20 y la D. Ad. $10^{\mathrm{a}}$.

Aquí, el centro de la atención no reside en la constitucionalidad misma del reconocimiento de extraterritorialidad, sino en que este se articule con la debida atribución a las CC. AA. de facultades para establecer niveles de protección diversos, llevar a cabo la comparación entre legislaciones y, en su caso, rechazar el reconocimiento por detectar que la legislación de la comunidad de origen no mantiene un nivel de protección equivalente. Desde esta vertiente, es en cómo regula las facultades de la comunidad de destino, dónde la LGUM vulneraría la CE: la LGUM automatiza el reconocimiento mutuo en un ámbito en el que no existe una armonización material detallada y, donde, por ese motivo, las CC. AA. deberían ostentar facultades necesarias para controlar si la legislación de origen protege de forma equiparable los mismos bienes jurídicos, derechos e intereses.

Este resultado debería haber implicado la inconstitucionalidad, total o parcial, no solo de los arts. 18.2. b), c) y e), 19 y 20, sino también de los arts. 5 y 17. En segundo lugar, debería haber ido acompañada de una sentencia interpretativa que validara el principio de eficacia nacional, concretando la inconstitucionalidad del reconocimiento mutuo automático en los supuestos de «extraterritorialidad horizontal»"

\section{PROPUESTA DE UN MODELO ALTERNATIVO}

La doctrina de la STC 79/2017 parece clara al admitir que el reconocimiento mutuo en ámbitos armonizados y la «extraterritorialidad plena» son instrumentos que responden a una misma realidad jurídica. Podría decirse que, en nuestro ordenamiento, el tipo «extraterritorialidad plena» se articula mediante el reconocimiento mutuo en una variante específica: el reconocimiento automático previa armonización estatal. Esto, como tratamos de exponer páginas atrás, es discutible, pues en la "extraterritorialidad plena» queda bastante difuminado el modelo regulativo y los elementos que estructuran el reconocimiento mutuo; dicho esto, de lo que no cabe duda es de que genéricamente sí que cabe afirmar que en los supuestos de "extraterritorialidad plena» tiene lugar el reconocimiento de la eficacia extraterritorial de las decisiones autonómicas.

La conexión entre «extraterritorialidad horizontal» y reconocimiento mutuo, sin embargo, no parece admitirse con la misma rotundidad por el

115 En contra de lo que nos tiene acostumbrados, el TC renuncia expresamente a ello (FJ 14). 
tribunal. Tampoco se quiere decir que el tribunal la rechace, sino que podría decirse que somete su constitucionalidad al cumplimiento de una serie de parámetros: a) el legislador estatal puede prever mecanismos de coordinación entre ordenamientos autonómicos para el reconocimiento de la eficacia extraterritorial de las actuaciones jurídico-administrativas de las CC. AA.; b) la armonización sustantiva, cuanto menos fijando estándares comunes (ex art. 149.1.1, 13 y 18) que ordenen cada actividad o sector, es presupuesto imprescindible para garantizar equivalencias normativas que permitan articular mecanismos de reconocimiento de las decisiones de la autoridad de origen; y c) esa aproximación de legislaciones debe hacerse preferentemente con un ámbito limitado, esto es, para sectores concretos de la actividad económica, y/o para afrontar supuestos singulares en los que se hayan identificado disfunciones o prácticas susceptibles de fragmentar el mercado nacional ${ }^{116}$.

A diferencia, por tanto, de la correlación entre un reconocimiento automático en ámbitos armonizados que se acopla con los supuestos de «extraterritorialidad plena», no existiría en nuestro ordenamiento una correspondencia igual de tajante entre reconocimiento mutuo condicionado en ámbitos sin o parcialmente armonizados y «extraterritorialidad horizontal». La sentencia, desde luego, veda la posibilidad del reconocimiento de eficacia extraterritorial sin una previa armonización sustantiva. Recuérdese que la reiterada calificación de la LGUM como una norma no armonizadora es clave para censurar que el Estado pueda articular un sistema general de reconocimiento. Esta conclusión es, sin embargo, discutible, en la medida en que la opción legislativa por un modelo general de reconocimiento no es exactamente una alternativa vacía de contenido sustantivo.

El reconocimiento de eficacia extraterritorial horizontal, como en esencia el reconocimiento mutuo, implica una programación normativa rica en

116 Este criterio censura que el legislador estatal opte por un modelo general de reconocimiento como la LGUM. A sensu contrario podríamos decir que sí sería constitucional que, con base en el art. 149.1.1, 13 y 18, se pudiera aprobar/modificar una ley específica con la misma finalidad. Por ejemplo, en el caso de la Ley de Ordenación del Comercio Minorista, por Ley 18/2014 se articuló la eficacia extraterritorial mediante una remisión general a la LGUM y a la Ley de Servicios. Tras la STC 79/2017, esa remisión queda sin sentido. Ahora bien, la pregunta es si podríamos entender constitucional que el legislador estatal incluyera en esa ley varios preceptos que regulasen el reconocimiento de eficacia extraterritorial. La respuesta habría de ser afirmativa, pues ni se podría decir que la Ley del Comercio Minorista es una ley no armonizadora, ni que es demasiado general. En fin, sería el modelo ya explicado de la normativa sobre tarjetas de estacionamiento para personas con discapacidad, así como de la colegiación obligatoria. 
contenidos formales que están orientados a articular las relaciones entre ordenamientos, así como las relaciones de cooperación entre Administraciones ${ }^{117}$. Que esto sea así, no puede servir para calificar a esta opción legislativa como una alternativa sin aparente trascendencia sustantiva, no apta para generar equivalencias básicas entre la normativa de las distintas CC. AA. Esto no es valorado suficientemente por la sentencia e, incluso, genera algunos problemas en comparación con otras leyes cuya constitucionalidad no ha sido cuestionada y que incorporan mecanismos similares en ámbitos igualmente amplios ${ }^{118}$.

Que el legislador estatal opte por un modelo regulativo general dirigido a articular el reconocimiento mutuo implica una configuración jurídica con una relevancia sustantiva determinante. En primer lugar, supone una apuesta por la coherencia interna del ordenamiento al extender el régimen jurídico de situaciones similares sujetas al derecho europeo a otras puramente domésticas ${ }^{119}$,

117 Sobre esta cuestión, véase J. Agudo González (2014).

118 Pensamos en la Ley de Servicios: aprobada con base en los mismos títulos competenciales, prevé una armonización limitada que se dedica fundamentalmente a la articulación del reconocimiento mutuo. Siguiendo los criterios de la STC 79/2017, no podría ser calificada como una norma armonizadora. De hecho, durante la tramitación de la ley también se plantearon dudas acerca de la conveniencia de abordar una armonización más detallada (Dictamen del Consejo de Estado 99/2009, de 18 de marzo). Una diferencia entre ambas leyes es el mayor ámbito de aplicación de la LGUM, pero este dato no puede determinar su inconstitucionalidad: el parámetro de control a estos efectos no puede derivar de una comparación cuantitativa entre leyes, ni de una comparación similar con una directiva (la que delimite el ámbito objetivo de la ley de servicios); en cuanto a lo segundo, entre otras razones, porque eso supondría una norma de derecho europeo como canon de control (SSTC 103/2015 o 21/2017). Un último dato distintivo es que la LGUM no transpone derecho europeo. Sin embargo, la doctrina constitucional ha reiterado que la incorporación de España en las CC.EE. no supuso alteración alguna del régimen de distribución de competencias: si el Estado, con base en el art. 149.1.1, 13 y 18, pudo aprobar una ley como la Ley de Servicios, podría hacer lo mismo sin que exista el deber de incorporar una Directiva europea. Ergo ¿por qué solo se ha puesto en tela de juicio la constitucionalidad de la LGUM? Como afirma J. Sola Teyssiere (2016: 211), algunas CC. AA. han sido muy críticas con la LGUM, pero no cuando se incorporan mecanismos similares para la ejecución del derecho europeo.

119 Un ordenamiento unitario y coherente es difícilmente compatible con admitir regímenes diferenciados en función de la aparición de un componente supranacional. En este sentido, J. González García (2004), «Globalización económica, Administraciones públicas y Derecho Administrativo: Presupuestos de una relación», Revista de Administración Pública, 164, págs. 7-39 (págs. 36 y ss.). Al respecto, véase la formulación de la «tesis del paralelismo» de E. Schmidt-Assmann (2003), La teoría general del Derecho Administrativo como sistema, Madrid: Marcial Pons, pág. 401. 
evitando así eventuales situaciones discriminatorias ${ }^{120}$. Segundo, presupone una ponderación favorable al ejercicio de derechos que, eso sí, generalmente tienen naturaleza económica ${ }^{121}$.

En tercer lugar, constituye una opción legislativa dirigida a la maximización de la efectividad de las relaciones jurídicas con proyección extraterritorial $^{122}$. Ese resultado se logra, en el plano formal, coordinando las relaciones entre ordenamientos jurídicos ${ }^{123}$ y con el consecuente establecimiento de relaciones cooperativas entre Administraciones autonómicas como modelo de articulación extraterritorial de la actuación administrativa ${ }^{124}$. Ade-

120 Si el derecho interno estableciese un régimen jurídico de mejor condición que el previsto para relaciones jurídicas similares en el derecho europeo, los principios de equivalencia y de efectividad operarían como instrumento favorable a la «igualación». Entre las opciones que presenta la CE, el legislador podría optar por ese mismo resultado cuando la situación es la inversa.

121 Esto implica positivizar una opción con trascendencia político-jurídica que ha sido criticada por fomentar un modelo económico liberal. No obstante, las SSTC 26/2012, 193/2013 o 209/2015 reiteran que el Estado puede legítimamente perseguir esos objetivos al amparo del art. 149.1.13.

122 La extraterritorialidad de las actuaciones jurídico-administrativas potencia las situaciones jurídicas nacidas administrativamente en un territorio determinado, para proyectarlas en relaciones jurídicas que se materializan más allá de ese territorio. El dinamismo que este planteamiento otorga a la relación jurídica supone que la posición jurídica del sujeto puede cambiar, en función del estado de la relación, lo que es consecuencia del sometimiento a diferentes ordenamientos y a distintas administraciones.

${ }^{123}$ La relación entre ordenamientos se concreta en la selección del derecho aplicable con base en la vertiente conflictual que define al principio de país de origen. Parte de la doctrina ha manejado la noción de «dumping regulatorio" para describir este efecto. La STC 79/2017 (13.b) critica también al principio de eficacia nacional instaurado por la LGUM por ese mismo motivo. Sin embargo, ese efecto es una consecuencia inherente al reconocimiento mutuo.

${ }^{124}$ La consecuencia es la interiorización de la distinción entre Administración de origen y Administración de destino o de acogida. En relación con la LGUM, véase J. Sola Teyssiere (2015), «Unidad de mercado y supervisión administrativa de las actividades económicas», Revista de Administración Pública, 197, págs. 133-174, y J. Sola Teyssiere (2016). Las funciones que ejercen una y otra: a) no se producen en un mismo lapso de tiempo; esto dependerá del momento en que el titular del derecho decida ejercerlo fuera de su comunidad de origen; y b) son funciones de intervención complementarias, pues la Administración de destino deberá tener en cuenta la decisión precedente y dictada en origen, y actuar consecuencia dentro de los límites del principio de proporcionalidad. 
más, en el plano sustantivo, aquel objetivo se consigue armonizando dos aspectos clave en toda actividad económica: el acceso a, y el ejercicio de, esa actividad $^{125}$.

Esta brevísima síntesis evidencia que esta opción legislativa no crea un marco de relaciones vacío. Establecer un sistema de reconocimiento implica per se armonizar con una trascendencia sustantiva evidente. Desde luego no significa introducir una regulación homogénea sobre los productos o los servicios en todo el territorio nacional que permita un reconocimiento mutuo automático de las decisiones de las CC. AA., pero sí que constituye una opción razonable y ajustada a las competencias del Estado allí donde carece de una competencia exclusiva y debe recurrir al art. $149.1,13$ y 18 .

El panorama que presentan estas alternativas constitucionales, en comparación con los cánones deducidos de la STC 79/2017, habilitaría también para reconocer la constitucionalidad del reconocimiento en supuestos de "extraterritorialidad horizontal» ${ }^{126}$ : a) la legislación estatal (tanto con base en títulos exclusivos, como compartidos y horizontales) puede armonizar con relevancia sustantiva variable ámbitos materiales con incidencia en materias de competencia de las CC. AA.; b) esa armonización estatal puede establecer mecanismos de reconocimiento, acompañados de previsiones y estándares sustantivos comunes más o menos desarrollados, sin perjuicio de admitir que, cuanto más pormenorizada sea la armonización, mayor base jurídica para la equivalencia entre ordenamientos habrá y, por ello, para establecer variantes

125 El reconocimiento mutuo determina las condiciones de acceso a una actividad económica concretada en la exigencia de una única actuación administrativa de control y, por ello, del sometimiento a un solo régimen jurídico. Ahora bien, el reconocimiento mutuo no exige que el acceso deba estar o no sujeto a la carga de obtener previa autorización. Esa circunstancia depende de la imposición de una política liberalizadora [SSTC 26/2012, 193/2013, 209/2015 y 79/2017 (FJ 7.b)] que puede o no «combinarse» con el reconocimiento mutuo. Y por lo que se refiere al ejercicio de las actividades económicas, una vez que tiene lugar el reconocimiento de la actuación administrativa de origen, la actividad se someterá plenamente al régimen jurídico de la comunidad de destino o de acogida. Esta nunca aplica el ordenamiento de origen.

126 Por el objeto de la STC 79/2017 no nos pronunciaremos ni sobre la «extraterritorialidad convencional» ni sobre la "extraterritorialidad unilateral» ad intra. No obstante, su constitucionalidad no puede cuestionarse, no solo por sus similitudes con la «extraterritorialidad horizontal», de modo que los argumentos que se dirán a continuación en el texto principal les son trasladables, sino también en virtud de la base constitucional y de los argumentos esgrimidos en la primera parte de este trabajo. 
de reconocimiento tendencialmente automático ${ }^{127}$; y c) en ámbitos armonizados parcialmente o con contenidos sustantivos limitados (ex arts. 149.1, 13 y 18), las CC. AA. deben ostentar la facultad para comparar las normas autonómicas dictadas en materias de su competencia, habilitándolas para proceder, en su caso, al reconocimiento (reconocimiento condicionado).

Obsérvese que la compatibilidad de la «extraterritorialidad horizontal» con el principio de territorialidad y el sistema de distribución de competencias estriba en que el reconocimiento de efectos extraterritoriales se ha de fundamentar en un acto de aceptación voluntaria por parte de la comunidad de destino (letra c). Esto significa que la variante del reconocimiento mutuo que es compatible con la CE solo puede ser aquella en la que el legislador estatal otorgue márgenes de ordenación y actuación suficientes como para que las CC. AA. puedan decidir voluntariamente: a) cómo ejercen sus competencias, por ejemplo, estableciendo una diversidad normativa inherente a la autonomía territorial que imponga condiciones adicionales al reconocimiento, siempre y cuando no sean desproporcionadas; $y \mathrm{~b}$ ) determinando, consecuentemente, si reconocen las decisiones administrativas dictadas por la comunidad de origen. En definitiva, en estos supuestos, el legislador estatal no podrá imponer una variante de reconocimiento automático; ahora bien, esto no impide que sean las propias CC. AA. las que fomenten con su normativa ese modelo.

Esta opción es más respetuosa con las competencias de las CC. AA. y claramente compatible con el sentido jurídico del principio de territorialidad: $\left.1^{\circ}\right)$ es más respetuosa de las competencias autonómicas porque el reconocimiento de la eficacia extraterritorial no implica necesariamente la adaptación de las competencias legislativas y ejecutivas de las CC. AA. a una previa armonización estatal. Lo que sí produce es una modulación horizontal del ejercicio de las competencias que afecta fundamentalmente a la comunidad de destino; y $2^{\circ}$ ) también es respetuosa con el principio de territorialidad, porque en ningún caso implica la usurpación del poder público de las CC. AA. en su jurisdicción territorial. Esto se debe a que la $\mathrm{CE}$ veda un reconocimiento que suponga el sometimiento al ordenamiento de origen de todas las vicisitudes jurídicas producidas a lo largo de la "vida» de una actividad económica. Una cosa es la compatibilidad del reconocimiento de actuaciones jurídicoadministrativas realizadas conforme a un ordenamiento equivalente, y otra bien distinta que la exclusividad del ordenamiento propio se vea suplantada íntegramente por el ajeno, desplazándole en cualquier acontecimiento de una

127 En este estrato se encontraría la difusa línea que distingue los supuestos de «extraterritorialidad plena», donde la centralización de la regulación difumina el sentido del reconocimiento mutuo, y los supuestos de «extraterritorialidad horizontal». 
relación jurídica con relevancia extraterritorial con base en una especie de fuero personal ${ }^{128}$. Este es el límite que el principio de territorialidad impone en el derecho público: las CC. AA. no aplican nunca normas ajenas, aunque sí pueden llegar a admitir la aplicación de esas normas en detrimento de las propias, vía reconocimiento de la eficacia extraterritorial.

${ }^{128}$ Así ya en los Acuerdos de la Comisión Bilateral de Cooperación Administración del Estado-Administración de la Comunidad Autónoma del País Vasco (Resolución de 17 de julio de 2014, de la Secretaría General de Coordinación Autonómica y Local) y de la Comisión Bilateral de Cooperación Administración General del Estado-Comunidad Autónoma de Galicia (Resolución de 14 de octubre de 2014, de la Secretaría General de Coordinación Autonómica y Local). 
